\title{
The role of public debt in the game of double chicken
}

Citation for published version (APA):

Beetsma, R., \& Bovenberg, A. L. (1995). The role of public debt in the game of double chicken. METEOR, Maastricht University School of Business and Economics. METEOR Research Memorandum No. 025 https://doi.org/10.26481/umamet.1995025

Document status and date:

Published: 01/01/1995

DOI:

10.26481/umamet.1995025

Document Version:

Publisher's PDF, also known as Version of record

\section{Please check the document version of this publication:}

- A submitted manuscript is the version of the article upon submission and before peer-review. There can be important differences between the submitted version and the official published version of record.

People interested in the research are advised to contact the author for the final version of the publication, or visit the DOI to the publisher's website.

- The final author version and the galley proof are versions of the publication after peer review.

- The final published version features the final layout of the paper including the volume, issue and page numbers.

Link to publication

\footnotetext{
General rights rights.

- You may freely distribute the URL identifying the publication in the public portal. please follow below link for the End User Agreement:

www.umlib.nl/taverne-license

Take down policy

If you believe that this document breaches copyright please contact us at:

repository@maastrichtuniversity.nl

providing details and we will investigate your claim.
}

Copyright and moral rights for the publications made accessible in the public portal are retained by the authors and/or other copyright owners and it is a condition of accessing publications that users recognise and abide by the legal requirements associated with these

- Users may download and print one copy of any publication from the public portal for the purpose of private study or research.

- You may not further distribute the material or use it for any profit-making activity or commercial gain

If the publication is distributed under the terms of Article $25 \mathrm{fa}$ of the Dutch Copyright Act, indicated by the "Taverne" license above, 


\title{
The Role of Public Debt in the Game of Double Chicken
}

\author{
Roel M.W.J. Beetsma \\ LIFE, University of Limburg, and CEPR \\ A. Lans Bovenberg \\ Central Planning Bureau and CEPR
}

\begin{abstract}
:
This paper explores how debt accumulation is affected by the strategic interactions between monetary and fiscal authorities. To achieve the second best with a dependent central bank, the government needs to be made both more conservative and more impatient. However, in the absence of political distortions, an optimally designed conservative, independent central bank is sufficient to establish the second best. In the presence of political distortions, however, also an optimal debt target is needed.
\end{abstract}

Keywords: Central bank independence, price stability weights, (optimal) debt targets, strategic debt management, political distortions, optimal preferences.

JEL codes: $\quad$ E52, E58, E61, E62.

July 1995

Mailing address:

Roel Beetsma

Department of Economics

University of Limburg

P.O.Box 616

6200 MD Maastricht

The Netherlands

* This paper was written while Beetsma was a postdoctoral fellow at DELTA (Joint Research Unit CNRS-EHESS-ENS). He thanks DELTA for the stimulating research environment. 


\section{Introduction}

Many countries have experienced substantial increases in public debt over the past two decades. The academic literature has explored public debt accumulation from two different perspectives. One perspective views public debt as a strategic instrument employed by current governments to affect the policies chosen by future governments. Persson and Svensson (1989), Aghion and Bolton (1989) and Alesina and Tabellini (1990) provide illustrations of this approach. Another strand of the literature explores the incentives to accumulate public debt by governments that are unable to commit to an announced inflation rate. Obstfeld $(1991 \mathrm{a}, \mathrm{b})$ demonstrates that, in the absence of commitment, governments may want to accumulate public assets in order to eliminate the incentives to generate unanticipated inflation, thereby enhancing the credibility of anti-inflation policies. ${ }^{1}$

This paper links both strands of the literature by studying the accumulation of public debt both for strategic reasons as well as the purpose of building up credibility. After presenting our two-period model in Section 2, the analysis is conducted in three steps. First, as a benchmark case, Section 3 considers a single, centralized, benevolent policymaker who selects both fiscal and monetary policy and who is able to commit. This benchmark case corresponds to the second-best equilibrium (i.e. the Pareto optimum in the absence of lump-sum taxes).

Section 4 takes the second step by assuming discretion rather than commitment. Debt policy is now affected by the so-called credibility effect (conform Obstfeld, 1991a,b), ${ }^{2}$ which induces the government to accumulate additional public assets in order to reduce inflation expectations in the future. In this way, the accumulation of public assets enhances the credibility of future anti-inflation policies.

The final step, taken in Section 5, extends Obstfeld's (1991a,b) analysis by allowing for decentralized monetary policymaking by an independent central bank, which lacks the ability to commit. This allows us to explore the strategic interaction between fiscal and monetary authorities. ${ }^{3}$ With centralized decision making, the inability to commit unambiguously reduces the accumulation of public debt. With decentralized decision making, in contrast, public debt may be boosted by the strategic interaction between the fiscal and monetary authorities. In particular, if the central bank is too conservative from the ex-ante perspective of the fiscal authority, the latter accumulates

\footnotetext{
${ }^{1}$ This second perspective on debt accumulation is closely related to the literature investigating how the term structure of public debt can help to establish the optimal commitment equilibrium. See, e.g., Lucas and Stokey (1983), Persson and Svensson (1984), Persson, Persson and Svensson (1987), Calvo and Obstfeld (1990) and Calvo and Guidotti (1992).

2 In Obstfeld (1991a,b), time-inconsistency originates in money demand, which depends on expected inflation. Our model, in contrast, is in the tradition of Barro and Gordon (1983a,b). In particular, non-indexed nominal wages are the source of time inconsistency.

${ }^{3}$ For the interactions between monetary and fiscal policies in a closed economy, see Sargent and Wallace (1981), Tabellini (1986), Alesina and Tabellini (1987), Debelle (1993), Levine and Pearlman (1992), Levine (1993), Debelle and Fischer (1994), Levine and Brociner (1994) and Krichel, Levine and Pearlman (1994).
} 
additional debt to encourage the central bank to produce higher future inflation. However, if the first-period fiscal authorities do not find the central bank conservative enough, they strategically reduce debt accumulation to induce the central bank to decrease inflation in the future. In this way, rather paradoxically, the discretionary equilibrium may result in a better performance in terms of long-run price stability than the commitment equilibrium, which produces less inflation in the short run. This result is closely related to Sargent and Wallace (1981) who show, with exogenously given fiscal policy, that tighter monetary control in the short run may boost inflation in the longer run. We demonstrate how this result may continue to hold in a explicit game-theoretic framework in which both monetary and fiscal policy are endogenously determined.

The strategic interaction between monetary and fiscal aurhorities in a dynamic framework allows us to deal with not only positive issues (including the impact on public debt and inflation over time) but also normative issues. In particular, the inability to commit gives rise to two additional sources of welfare losses compared to the second best. One, familiar source is intratemporal: the monetary authorities attempt to alleviate distortions in the real economy by stimulating output through unanticipated inflation. With the private sector anticipating these attempts, however, monetary policy is ineffective in boosting output in equilibrium. Accordingly, the equilibrium inflation rate exceeds the socially optimal rate.

The other, less familiar, source of welfare loss produced by discretionary policy involves the intertemporal distribution of distortionary losses. From the perspective of a discretionary policymaker who sets policy in the first period, first-period expectations are pre-determined. The corresponding expectations in the second period, in contrast, still have to be determined and thus can be affected by policy. This induces the policymaker to use unanticipated inflation in the first period, thereby in effect exploiting the exogenous first-period inflation expectations, to impact inflation expectations in the second period. However, in equilibrium, the private sector correctly anticipates these incentives facing policymakers to use first-period unanticipated inflation in this way. In a dynamic model, therefore, the inability to commit yields not only intra- but also intertemporal distortions.

These welfare losses can be eliminated by properly designed institutions. Adjusting monetary policy preferences is the most direct way to deal with the distortions due to the inability to commit. Indeed, with an independent central bank (i.e. decentralized monetary policymaking) and in the absence of political distortions, both sources of welfare loss vanish if the central bank's price stability weight is adjusted optimally. Intuitively, the incentive facing the first-period fiscal authorities to use debt policy strategically originates in sub-optimal monetary policies in the second period. If the central bank features the optimal preferences from a social point of view, the fiscal authorities no longer perceive the need to use debt policy to bring future monetary policy closer to the optimum. With a dependent central bank (i.e. centralized policymaking), the government needs to be made not only more inflation averse than an independent central bank but also more impatient than society. 
If political distortions cause the preferences of the fiscal authorities to depart from those of society, an optimally designed, conservative independent central bank is no longer sufficient to reach the second best. Intuitively, changing monetary institutions is not the proper instrument to deal with imperfect fiscal institutions. Indeed, to achieve the second best in the presence of political distortions, not only monetary but also fiscal institutions should be dealt with. In particular, properly adjusting the price stability weight of the central bank removes the distortions due to the inability to commit while debt ceilings avoid excessive debt accumulation by myopic fiscal authorities who are more impatient than society or by opportunistic authorities who care less about price stability than society does. In this way, institutional arrangements for monetary and fiscal policy are targetted directly at the distortions due to the inability to commit and the existence of imperfect fiscal institutions.

If fiscal instruments, including debt ceilings, are not available, monetary institutions have to deal with fiscal imperfections. If fiscal authorities are more impatient than society, for example, the central bank should be made less conservative than in the absence of political distortions. This in order to encourage the myopic fiscal authorities to restrain debt accumulation so as to enhance the credibility of monetary policy. Accordingly, monetary policy is distracted from its primary mission (i.e. price stability) because it is used as an indirect instrument to deal with imperfections in fiscal policy. This explains why central bankers are strong advocates of ceilings on public debt when designing institutions for the European Monetary Union (EMU).

\section{The model}

This section formulates a two-period model with homogeneous product markets and a unionized labour market. Within this framework, we set up a game between three players: a union representing workers and two policy authorities, namely a fiscal authority (the government) and a monetary authority (the central bank).

\subsection{Output and preferences}

The sole objective of unions is to achieve a target real wage rate, the logarithm of which we normalize to zero. ${ }^{4}$ Therefore, the $(\log )$ of the nominal wage rate in period $t$ is set equal to the (rationally) expected (log) price level in period $t, p_{t}^{e}$. Nominal wage contracts are signed before policy is selected. Unions thus act as Stackelberg leaders vis-à-vis policymakers.

Output is given by $Y_{t}=I_{t}{ }^{\eta}(0<\eta<1)$, where ${ }_{t} L$ is labor, and is taxed at a rate $\tau$. The representative firm selects employment so as to maximize profits $P_{t} L_{t}{ }^{\eta}\left(1-\tau_{t}\right)-W_{t} L_{t}$, where $P_{t}$ and $W_{t}$

\footnotetext{
${ }^{4}$ For similar approaches, see Alesina and Tabellini (1987), Debelle (1993), Debelle and Fischer (1994) and Jensen (1994).
} 
denote the price level and the wage rate, respectively. Hence, $(\log )$ output is given by $y_{t}=(\eta /(1-$ $\eta))\left(\pi_{t}-\pi_{t}{ }^{e}-\tau_{t}+\log \eta\right)$, where $\pi$ is the inflation rate ${ }_{t}{ }_{t}$ and $\pi$ the expected inflation rate. For convenience, we normalize output by subtracting the constant $(\eta /(1-\eta)) \log \eta$ from $y_{t}$. Hence, normalized output, $x_{t}$, amounts to

$$
x_{t}=v\left(\pi_{t}-\pi_{t}^{e}-\tau_{t}\right), v \equiv \eta /(1-\eta)
$$

Without tax distortions, $x_{\mathrm{t}}=0$ in a rational expectations equilibrium (where inflation is anticipated, i.e. $\pi_{t}=\pi_{t}^{e}$, see (2.1)). In addition to distortionary output taxes, we allow for other, nontax, distortions due to, for example, union power in the labor market or monopoly power in commodity markets. The first-best output level, i.e. output with neither tax nor non-tax distortions, is denoted by $\tilde{x}_{t}$. Thus, $\tilde{x}_{t}>0$ measures the non-tax distortions and can be interpreted as an implicit tax on output. In fact, by offsetting the implicit output tax, an output subsidy $\left(\tau_{t}=-\tilde{x}_{t} / \nu\right)$ can raise output towards its first-best level $\tilde{x}_{\text {- }}$

Society features a social welfare function that differs from the objectives of the unions because the social welfare function accounts for the preferences of not only workers but also nonworkers. In particular, society's preferences, defined over inflation, output and public spending, are represented by the following loss function,

$$
\mathrm{V}_{\mathrm{S}}=1 / 2 \sum_{\mathrm{t}=1}^{2} \beta_{\mathrm{S}}^{\mathrm{t}-1}\left[\alpha_{\pi \mathrm{S}} \pi_{\mathrm{t}}^{2}+\left(\mathrm{x}_{\mathrm{t}}-\tilde{\mathrm{x}}_{\mathrm{t}}\right)^{2}+\alpha_{\mathrm{gS}}\left(\mathrm{g}_{\mathrm{t}}-\tilde{\mathrm{g}}_{\mathrm{f}}\right)^{2}\right], 0<\beta_{\mathrm{S}} \leq 1, \alpha_{\pi \mathrm{S}}, \alpha_{\mathrm{gS}}>0
$$

Welfare losses increase in the deviations of inflation, $(\log )$ output and government spending $\left(\mathrm{g}_{\mathrm{t}}\right.$ is government spending as a share of non-distortionary output) from their targets (or first-best levels or 'bliss points'). ${ }^{5}$ The target level of inflation corresponds to price stability. The non-distortionary output level, $\tilde{x}_{t}$, represents the bliss point for output. The first-best level of government spending, $\tilde{\mathbf{g}}_{\mathrm{t}}$, can be interpreted as the optimal share of non-distortionary output to be spent on public goods if (non-distortionary) lump-sum taxes would be available (see Debelle and Fischer, 1994). The parameters $\alpha_{\pi \mathrm{S}}$ and $\alpha_{\mathrm{gS}}$ correspond to the weights of the price stability and government spending objectives, respectively, relative to the output objective. The limiting case of $\alpha_{\mathrm{gS}} \rightarrow \infty$ corresponds to the situation where government spending is exogenously fixed at $\tilde{g}$. Finally, $\beta_{\mathrm{S}}$ denotes society's subjective discount factor.

Preferences of the fiscal and monetary authorities are likewise given by, respectively,

$$
V_{\mathrm{F}}=1 / 2 \sum_{\mathrm{t}=1}^{2} \beta_{\mathrm{F}}^{\mathrm{t}-1}\left[\alpha_{\pi \mathrm{F}} \pi_{\mathrm{t}}^{2}+\left(\mathrm{x}_{\mathrm{t}}-\tilde{\mathrm{x}}_{\mathrm{t}}\right)^{2}+\alpha_{\mathrm{gS}}\left(\mathrm{g}_{\mathrm{t}}-\tilde{\mathrm{g}}_{\mathrm{t}}\right)^{2}\right], 0<\beta_{\mathrm{F}} \leq 1 \text { and } \alpha_{\pi \mathrm{F}}>0
$$

and

$$
\mathrm{V}_{\mathrm{M}}=1 / 2 \sum_{\mathrm{t}=1}^{2} \beta_{\mathrm{S}}^{\mathrm{t}-1}\left[\alpha_{\pi \mathrm{M}} \pi_{\mathrm{t}}^{2}+\left(\mathrm{x}_{\mathrm{t}}-\tilde{\mathrm{x}}_{\mathrm{t}}\right)^{2}+\alpha_{\mathrm{gS}}\left(\mathrm{g}_{\mathrm{t}}-\tilde{\mathrm{g}}_{\mathrm{f}}\right)^{2}\right], \alpha_{\pi \mathrm{M}}>0
$$

\footnotetext{
${ }^{5}$ Employment is directly related to output through the production function. Hence, instead of output, employment could have been included as an argument in the loss function, with the target employment level corresponding to the output level in absence of any distortions.
} 
The price stability weights of the two policy authorities do not have to coincide. Moreover, these weights can differ from society's price stability weight. A policymaker with a higher price stability weight will be termed to be more conservative. Political distortions are present if the government's preferences depart from society's. In particular, a government that cares less about inflation than society does (i.e. $\alpha_{\pi \mathrm{F}}<\alpha_{\pi \mathrm{S}}$ ) is called opportunistic. A government is myopic if its subjective discount factor is lower than that of society (i.e $\beta_{\mathrm{F}}<\beta_{\mathrm{S}}$ ). Such a high rate of time preference may be due to, for example, a high probability of being voted out of office at the end of the first period. ${ }^{6}$

\subsection{The government financing requirement}

The government budget constraint in each period is given by (see, e.g., Beetsma and Bovenberg, 1995)

$$
g_{t}+(1+\rho) d_{t-1}=\tau_{t}+\kappa \pi_{t}+d_{t}, t=1,2
$$

where $\rho$ denotes the (constant) real interest rate ${ }^{7}$ and $\tau_{t}$ and $\kappa>0$ represent, respectively, distortionary tax revenue and real money holdings as shares of (non-distortionary) output. ${ }^{8}$ Seigniorage revenues equal $\kappa \pi_{t}$. Furthermore, $d_{-1}$ stands for the stock of public debt carried over from the previous period, while $d_{t}$ denotes newly issued public debt. All public debt is real and matures after one period. Moreover, all debt is paid off at the end of the second period (i.e. $d_{2}=0$ ).

The government budget constraint in both periods can be consolidated into a single intertemporal government budget constraint,

$$
(1+\rho) d_{0}+g_{1}+g_{2} /(1+\rho)=\tau_{1}+\kappa \pi_{1}+\left(\tau_{2}+\kappa \pi_{2}\right) /(1+\rho)
$$

The left-hand side of (2.6) represents discounted public spending (including repayment of the initial stock of debt). Discounted public revenues are given by the right-hand side of (2.6). For later convenience, we derive what we term the government financing requirement, by rewriting $(2.5)$ as

$$
\mathrm{GFR}_{\mathrm{t}}=\mathrm{K}_{\mathrm{t}}+(1+\rho) \mathrm{d}_{\mathrm{t}-1}-\mathrm{d}_{\mathrm{t}}=\left[\tau_{\mathrm{t}}+\tilde{\mathrm{x}}_{\mathrm{t}} / v\right]+\kappa \pi_{\mathrm{t}}+\left[\tilde{\mathrm{g}}_{\mathrm{t}}-\mathrm{g}_{\mathrm{t}}\right] \text {, where } \mathrm{K}_{\mathrm{t}}=\tilde{\mathrm{g}}_{\mathrm{t}}+\tilde{\mathrm{x}}_{\mathrm{t}} / v
$$

\footnotetext{
${ }^{6}$ Cukierman, Edwards and Tabellini (1992) show explicitly how the degree of political instability affects the effective rate of time preference of the government in a model in which the choice of the efficiency of the tax structure plays a similar strategic role as debt does in this paper.

7 This is the rate of return on public debt required by a risk neutral investor who has an outside investment opportunity paying a real rate of return $\rho$.

${ }^{8}$ Alesina and Tabellini (1987), Debelle (1993) and Jensen (1994), among others, assume that $\kappa=1$. However, as will become clear below, non-unitary values for $\kappa$ play an important role in our analysis.
} 
The government financing requirement $\left(\mathrm{GFR}_{t}\right)$ amounts to the government spending target $\tilde{\mathrm{g}}, \mathrm{t}^{\mathrm{a}}$ labor subsidy aimed at offsetting the implicit tax on output, $\tilde{x}_{t} / v$, and the cost of servicing outstanding public debt net of newly issued debt, $(1+\rho) \mathrm{d}_{\mathrm{t}-1}-\mathrm{d}_{\mathrm{t}}$. The last right-hand side of (2.7) represents the sources of finance: explicit and implicit tax revenues, $\tau_{\mathrm{t}}+\tilde{\mathrm{x}} / \mathrm{v}$, seigniorage revenues, $\kappa \pi_{\mathrm{t}}$, and the shortfall of government spending from its target, $\tilde{\mathrm{g}}_{\mathrm{t}} \mathrm{g}_{\mathrm{t}}$.

If we take the discounted (to period 1) sums of the left and right hand sides of (2.7) (for $\mathrm{t}=1,2)$, we obtain the intertemporal government financing requirement,

$$
\mathrm{F} \equiv(1+\rho) \mathrm{d}_{0}+\mathrm{K}_{1}+\mathrm{K}_{2} /(1+\rho)=\sum_{\mathrm{t}=1}^{2}(1+\rho)^{-(\mathrm{t}-1)}\left[\left(\tau_{\mathrm{t}}+\tilde{\mathrm{x}}_{\mathrm{t}} / v\right)+\kappa \pi_{\mathrm{t}}+\left(\tilde{\mathrm{g}}_{\mathrm{t}}-\mathrm{g}_{\mathrm{f}}\right)\right]
$$




\section{Centralized policymaking with commitment}

In this section, the central bank is dependent. Accordingly, the government selects not only tax rates and public spending but also inflation. Furthermore, as a benchmark for the more realistic, discretionary equilibria analyzed below, this section assumes that the government is able to commit. The government thus credibly announces its monetary policy each period before expectations are formed. Therefore, expectations are perceived to be endogenous not only in the second but also in the first period, so that the government takes into account the rational expectations constraint $\left(\pi_{t}{ }^{e}=\pi_{t}\right)$ in both periods. With a benevolent government (i.e. a government that shares society's preferences), commitment leads to the second best (i.e. the Pareto optimum in absence of lump-sum taxes).

We can solve for the commitment equilibrium by working backwards in time. ${ }^{10}$ The policy outcomes and welfare losses in the second period are computed for given $d_{1}$, and therefore coincide with the corresponding outcomes in what we will refer to in the following as the static version of the) model (i.e. the single-period version of the model with an exogenous stock of public debt $\mathrm{d}_{1}$; see Beetsma and Bovenberg, 1995). The government's second period welfare losses are (given $d_{1}$ and given that the second period policy instruments are selected optimally) is $1 / 2 \mathrm{P}^{-1}\left[\mathrm{~K}_{2}+(1+\rho) \mathrm{d}_{1}\right]^{2}$, where $\mathrm{P} \equiv \kappa^{2} / \alpha_{\pi \mathrm{F}}+1 / v^{2}+1 / \alpha_{\mathrm{gg}}$. Hence, substituting (2.1) into (2.3) and imposing ${ }^{\mathrm{e}} \pi_{1}=\pi$, the firstperiod Lagrangian, to be optimized over $\pi_{1}, \tau_{1}, \mathrm{~g}_{1}$ and $\mathrm{d}_{1}$, amounts to

$$
\begin{gathered}
\mathcal{L}=1 / 2\left[\alpha_{\pi \mathrm{F}} \pi_{1}^{2}+\left(v \tau_{1}+\tilde{\mathrm{x}}_{1}\right)^{2}+\alpha_{\mathrm{gS}}\left(\mathrm{g}_{1}-\tilde{\mathrm{g}}_{1}\right)^{2}\right]+1 / 2 \beta_{\mathrm{F}} \mathrm{P}^{-1}\left[\mathrm{~K}_{2}+(1+\rho) \mathrm{d}_{1}\right]^{2}+ \\
\lambda_{1}\left[\mathrm{~g}_{1}+(1+\rho) \mathrm{d}_{0}-\tau_{1}-\mathrm{k} \pi_{1}-\mathrm{d}_{1}\right],
\end{gathered}
$$

where $\lambda_{1}$ represents the marginal costs of public funds (i.e. the Lagrange multiplier of the government budget constraint). Optimizing the Lagrangian above, we arrive at the following firstorder conditions for inflation, taxation, public spending and public debt, respectively,

$$
\begin{gathered}
\alpha_{\pi \mathrm{F}} \pi_{1}=\lambda_{1} \kappa, \\
v\left(v \tau_{1}+\tilde{\mathrm{x}}_{1}\right)=\lambda_{1}, \\
\alpha_{\mathrm{gS}}\left(\tilde{\mathrm{g}}_{1}-\mathrm{g}_{1}\right)=\lambda_{1}, \\
\beta_{\mathrm{F}} \mathrm{P}^{-1}\left[\mathrm{~K}_{2}+(1+\rho) \mathrm{d}_{1}\right](1+\rho)=\lambda_{1} .
\end{gathered}
$$

\section{Public debt}

Combining (3.2)-(3.4) with the government financing requirement (2.7) for the first period, we find

\footnotetext{
${ }^{9}$ In the discretionary equilibria analyzed below, in contrast, first-period expectations are perceived to be exogenously given when policy is set in the first period. The same holds true for the second period expectations when policies are set in the second period.

${ }^{10}$ Appendix A provides a complete derivation of the equilibrium outcomes.
} 
$v\left(v \tau_{1}+\tilde{\mathrm{x}}_{1}\right)=\mathrm{P}^{-1}\left[\mathrm{~K}_{1}+(1+\rho) \mathrm{d}_{0}-\mathrm{d}_{1}\right]$. Substituting this into (3.3) and combining with (3.5), we arrive at

$$
\left[\mathrm{K}_{1}+(1+\rho) \mathrm{d}_{0}-\mathrm{d}_{1}\right]=\beta_{\mathrm{F}}(1+\rho)\left[\mathrm{K}_{2}+(1+\rho) \mathrm{d}_{1}\right]
$$

The left hand side of (3.6) represents the marginal benefit in the first period of issuing more debt, while the right hand side represents the (discounted) marginal cost in the form of larger distortionary losses in the second period on account of the higher debt servicing costs. Other things equal, the discounted cost is lower, the lower the discount factor $\beta_{\mathrm{F}}$. Due to the quadratic specification of the loss function, the marginal benefit (in the first period) associated with an increase in debt at the end of the first period is decreasing in $d_{1}$, while the marginal cost (in the second period) of such an increase is increasing in $d_{1}$.

We can rewrite (3.6) as follows:

$$
\left[\beta_{\mathrm{F}}^{*}(1+\rho)+1\right] d_{1}=\left[\mathrm{K}_{1}+(1+\rho) \mathrm{d}_{0}-\mathrm{K}_{2}\right]+\left(1-\beta_{\mathrm{F}}^{*}\right) \mathrm{K}_{2} \text {, where } \beta_{\mathrm{F}}^{*}=\beta_{\mathrm{F}}(1+\rho) \text {. }
$$

The right hand side of (3.7) reveals the two determinants of debt accumulation under commitment. The term between square brackets represents the so-called smoothing effect. This effect raises (reduces) $d_{1}$ whenever the exogenous component of the government financing requirement in the first period, $\mathrm{K}_{1}+(1+\rho) \mathrm{d}_{0}$, exceeds (falls short of) the exogenous component of the government financing requirement in period two, $\mathrm{K}_{2}$.

The second term at the right hand side of (3.7) stands for the intertemporal substitution effect. This effect raises (reduces) public debt if impatience as measured by the subjective rate of time preference exceeds (falls short of) the rate of return on assets. For later convenience, we note from (3.7) that $d_{1}$ is decreasing in $\beta_{\mathrm{F}}{ }^{*}$, i.e. $\partial \mathrm{d}_{1} / \partial \beta_{\mathrm{F}}{ }^{*}<0$.

\section{Inflation, taxes, and public spending}

The policy outcomes are contained in Table 1. The shares of the government financing requirement (GFR) absorbed by seigniorage $\left(\kappa \pi_{t}\right)$, the sum of explicit and implicit taxes $(\tau+\tilde{\mathrm{x}} / \nu)$ and the public spending gap $\left(\tilde{\mathrm{g}}_{\mathrm{t}} \mathrm{g}_{\mathrm{t}}\right)$ are the same in each period and are, in fact, equal to the corresponding shares in the static version of the model (see Beetsma and Bovenberg, 1995, Table 1 (where $v=1$ )). If $\beta_{\mathrm{F}}{ }^{*}=1$, the government financing requirements are perfectly smoothed out over both periods. Hence, inflation, total taxes and the public spending gap are constant over time. If $\beta_{\mathrm{F}}^{*}<1$, first-period welfare losses are relatively important compared to the return on assets. Accordingly, inflation, seigniorage, taxes and the government spending are rising over time. ${ }^{11}$

\section{Welfare} 1987).

${ }^{11}$ The model predicts that the financing sources of the government move jointly over time (cf. Mankiw, 
Society's discounted social welfare loss contained in Table 2 is derived by substituting the policy outcomes from Table 1 into expression (2.2) and using that, in equilibrium, $\pi_{t}{ }^{e}=\pi_{t}, t=1,2$. The term between the first square brackets in the welfare expression in Table 2 stems from the intratemporal distribution of distortionary losses and reaches a minimum for $\alpha_{\pi \mathrm{F}}=\alpha_{\pi \mathrm{s}}$. The term between the second square brackets (i.e. $\delta_{C}^{2}\left(\left(\beta_{C}{ }^{*}\right)^{2}+\beta_{S}\right)$, where $\delta_{C} \equiv(1+\rho) /\left(\beta_{C}^{*}(1+\rho)+1\right)$ and $\beta^{*} \equiv \beta^{*}$, and where the subscript $C$ denotes the regime of "centralized commitment") orginates in the intertemporal distribution of distortionary losses and reaches a minimum for $\beta_{\mathrm{F}}=\beta_{\mathrm{S}}{ }^{12}$ Hence, with commitment, the second best (i.e. the Pareto optimum in absence of lump-sum taxes) is reached if the government's preferences coincide with society's. Political distortions result in additional welfare losses.

\section{The optimal debt target}

In the United States, a number of recent proposals have been put forward to balance the federal public budget. Furthermore, the Maastricht treaty includes ceilings on public debt as entrance requirements for the EMU. We now explore the welfare effects of a debt target within the framework of our model. In the presence of a target $d_{1}$ on public indebtedness, the government solves two single period optimisation problems with exogenous government financing requirements $\mathrm{K}_{1}+(1+\rho) \mathrm{d}_{0}-\mathrm{d}_{1}$ and $\mathrm{K}_{2}+(1+\rho) \mathcal{q}$ in the first and second period, respectively. Given that inflation, taxes and public spending are selected optimally by the policymaker in each period, society's discounted welfare loss amounts to

$$
\frac{1}{2 \mathrm{P}}\left(\left(\tilde{\mathrm{K}}_{1}+(1+\rho) \mathrm{d}_{0}-\hat{\mathrm{d}}_{1}\right)^{2}+\beta_{\mathrm{S}}\left(\tilde{\mathrm{K}}_{2}+(1+\rho) \hat{\mathrm{d}}_{1}\right)^{2}\right)
$$

A lower debt target $d_{1}$ shifts welfare losses from the second towards the first period. The optimal debt target minimises the term between brackets and is thus given by ${ }^{13}$

$$
\hat{\mathrm{d}}_{1}^{\mathrm{opt}}=\frac{\tilde{\mathrm{K}}_{1}+(1+\rho) \mathrm{d}_{0}-\tilde{\mathrm{K}}_{2}+\left(1-\beta_{\mathrm{S}}^{*}\right) \tilde{\mathrm{K}}_{2}}{\beta_{\mathrm{S}}^{*}(1+\rho)+1} \text {, where } \beta_{\mathrm{S}}^{*} \equiv \beta_{\mathrm{S}}(1+\rho) \text {. }
$$

In fact, a debt target equal to $\mathrm{d}_{1}{ }^{\text {opt }}$ implies an optimal intertemporal allocation of distortions, so that the economy attains the second best if $\alpha_{\pi \mathrm{F}}=\alpha_{\pi \mathrm{S}}$. For a government featuring a discount factor $\beta_{\mathrm{F}}=\beta_{\mathrm{S}}$, $\mathrm{d}_{1}{ }^{\text {opt }}$ equals $\mathrm{d}_{1}$ implied by (3.7). Hence, in the absence of political distortions, arbitrary (in contrast to the optimal) debt targets are costly. With myopic policymakers, however, the imposition of the optimal debt enhances welfare by protecting society from excessive debt accumulation by a myopic

12 The function $(1+\rho)^{2}\left(z^{2}+\beta_{S}\right) /(z(1+\rho)+1)^{2}$ is decreasing in $z$ for $z<\beta_{S}(1+\rho)$, increasing for $z>\beta_{S}(1+\rho)$ and, hence, attains a global minimum for $\mathrm{z}=\beta_{\mathrm{S}}(1+\rho)$. Therefore, the second component of the welfare loss is minimized for $\beta_{\mathrm{F}}{ }^{*}=\beta_{\mathrm{F}}(1+\rho)=\beta_{\mathrm{S}}(1+\rho)$, hence for $\beta_{\mathrm{F}}=\beta_{\mathrm{S}}$.

$13 \mathrm{~d}_{1}$ does not interact with the intratemporal allocation of distortions. Therefore, (3.9) describes the optimal debt target also if the policymaker is opportunistic $\left(\alpha_{\pi \mathrm{F}}<\alpha_{\pi \mathrm{S}}\right)$. 
policymaker $\left(\beta_{\mathrm{F}}<\beta_{\mathrm{S}}\right)$.

\section{Centralized policymaking with discretion}

In this section, the central policymaker is not able to commit. When discretionary policies are selected in the first period, inflation expectations for that period are taken to be exogenously given because the private sector acts as a Stackelberg leader in concluding nominal wage contracts. However, expectations of second period inflation still need to be formed and, hence, can be affected by first-period policy. Indeed, as we will see below, the government may want to use its debt policy to affect second-period inflation expectations.

\section{Public debt}

Employing a similar procedure as in the case of centralized commitment (in Section 3), we find the optimal debt level from the following first-order condition for public debt:

$$
\left[\mathrm{K}_{1}+(1+\rho) \mathrm{d}_{0}-\mathrm{d}_{1}\right]=\beta_{\mathrm{F}}(1+\rho)\left(\mathrm{D}^{*} / \mathrm{D}\right)\left[\mathrm{K}_{2}+(1+\rho) \mathrm{d}_{1}\right]
$$

where $\mathrm{D} \equiv \kappa(\kappa+1) / \alpha_{\pi \mathrm{F}}+1 / \nu^{2}+1 / \alpha_{\mathrm{gS}}$ and $\mathrm{D}^{*} \equiv(\kappa+1)^{2} / \alpha_{\pi \mathrm{F}}+1 / \nu^{2}+1 / \alpha_{\mathrm{gS}}$. As in the corresponding expression (3.6) in Section 3, the left-hand side of (4.1) represents the marginal benefit (in period one) from issuing more debt, while the right-hand side stands for the marginal cost (in period two). By comparing (3.6) from the commitment equilibrium with (4.1) from the discretionary equilibrium, we observe that discretionary debt accumulation is affected by another effect in addition to the smoothing and intertemporal substitution effects. This so-called credibility effect, which arises from the inability to commit, is represented by the factor $D^{*} / D>1$ at the right-hand side of (4.1). This factor effectively increases the discount factor, thereby raising the second-period costs associated with additional debt. Therefore, with centralisation, the stock of public debt, $\mathrm{d}_{1}$, is in general lower under discretion than under commitment (recall that $\partial \mathrm{d}_{1} / \partial \beta_{\mathrm{F}}^{*}<0$ ).

The intuition for the lower stock of debt in the discretionary equilibrium is the following (see also Obstfeld, 1991a,b). Whereas first-period inflation expectations are perceived as given by the policymaker when selecting debt policy, second-period inflation expectations can still be affected. Hence, to reduce the "stock of credibility problems" in the second period, as measured by the government financing requirement $\mathrm{K}_{2}+(1+\rho) \mathrm{d}_{1}$, the government reduces public debt, thereby mitigating the inflationary bias in the second period. In other words, the government trades off additional distortionary losses in the first period against gains in credibility of monetary policy in the second period.

The inability to commit exerts a large effect on debt policy if anti-inflation monetary policy is not very credible. A steep slope of the Phillips curve (i.e. a large v) harms the credibility of antiinflation policies because it raises the boost to output from inflation surprises. Accordingly, it 
requires more asset accumulation to build up credibility. Similarly, a high priority for public spending (i.e. a large weight $\alpha_{\mathrm{gs}}$ ), by requiring higher output taxes, raises the incentive to use unanticipated inflation to alleviate tax distortions and, hence, also boosts asset accumulation. High priority to price stability (i.e. a large weight $\alpha_{\pi \mathrm{F}}$ ) raises second-period credibility of low inflation policies, thereby reducing the need to accumulate public assets (note that $\beta_{D}^{*}=\beta(1+\rho)\left(D^{*} / D\right)$ is decreasing in $\alpha_{\pi \mathrm{F}}$ ). In fact, if $\alpha_{\mathrm{rF}} \rightarrow \infty$, second period inflation and, therefore, also the second period inflation bias, are zero, irrespective of the size of the government financing requirement. In that case, the first-period government sees no need to accumulate assets for the purpose of building up credibility. In other words, a high price stability weight of the government substitutes for asset accumulation in enhancing the credibility of second-period monetary policy.

\section{Inflation}

The accumulation of public assets shifts distortionary losses from the second to the first period. In the special case of $\mathrm{K}_{1}=\mathrm{K}_{2}, \mathrm{~d}_{0}=0$ and $\beta_{\mathrm{F}}{ }^{*}=1$, policy variables are constant over time under commitment. Under discretion, in contrast, inflation and taxation are falling over time ${ }^{14}$ while government spending and output are rising.

Assume for the moment that $\alpha_{\pi \mathrm{F}}=\alpha_{\pi \mathrm{S}}$. In the static version of the model, inflation is higher under discretion than under commitment. However, the incentive to build up additional public assets in the dynamic model of this paper implies that distortionary losses are shifted away from the second to the first period. This may reverse the "standard" ranking. In particular, second-period inflation is lower under discretion than under commitment, if (see Appendix B),

$$
\left(\frac{\beta_{\mathrm{F}}^{*}(1+\rho)}{\beta_{\mathrm{F}}^{*}(1+\rho)+1}\right)\left(\frac{\kappa(\kappa+1)}{\alpha_{\pi \mathrm{S}}\left(1 / v^{2}+1 / \alpha_{\mathrm{gS}}\right)}\right)>1 .
$$

This condition is met if the negative effect on second-period inflation associated with the accumulation of public assets on account of the credibility effect dominates the familiar inflation bias due to discretion. Accordingly, condition (4.2) is more likely to be met if the credibility effect is important. As explained above, this is the case if the Phillips curve is steep and society attaches a low priority to price stability compared to public spending. Large money holdings, $\kappa$, make

\footnotetext{
${ }^{14}$ This is related to a result on optimal capital taxation due to Chamley (1986). He finds that the optimal policy of a government is to reduce the tax rate on capital over time. The reason is that the initial stock of capital is inelastically supplied. Here, a similar effect arises. Since inflation expectations in existing wage contracts are perceived to be "inelastic", the government finds it optimal to impose a high initial inflation tax, which contributes to the accumulation of assets and builds up credibility of future policy. However, our set up differs fundamentally from that of Chamley (1986). In particular, policies are time consistent in the current model because inflation expectations are endogenous and rational in equilibrium. Hence, the private sector correctly anticipates the incentives of the public sector to impose a high inflation tax in the short run. This is in contrast to Chamley (1986), who assumes that the stock of capital is exogenously fixed in the short run and thus not affected by the incentive facing the government to tax the capital stock in the short run. In Chamley (1986), who assumes commitment, the derived policy is socially optimal, given the absence of lumpsum taxes. As is explained below, the time-consistent equilibrium derived in the current paper is not optimal.
} 
condition (4.2) easier to satisfy by reducing the importance of the traditional inflation bias under discretion. ${ }^{15}$ In particular, even under commitment, authorities rely relatively heavily on seigniorage to cover their financing requirement if money holdings are large. More generally, condition (4.2) reveals that tighter short-run monetary policy (under commitment) may yield higher inflation (compared to discretion) in the long run if large money holdings imply that inflation exerts powerful effects on the public finances.

\section{Welfare}

An expression for the welfare loss is contained in Table 2. Just like in the commitment case, the welfare loss can be decomposed in intratemporal losses (the term in the first square brackets) and an intertemporal losses (the term in the second square brackets).

If the government's preferences coincide with society's, both of these losses under discretion exceed the corresponding second-best losses under commitment. As regards the intratemporal loss, we have

$$
\left(\frac{\frac{(\kappa+1)^{2}}{\alpha_{\pi \mathrm{S}}}+\frac{1}{v^{2}}+\frac{1}{\alpha_{\mathrm{gS}}}}{\left(\frac{\kappa(\kappa+1)}{\alpha_{\pi \mathrm{S}}}+\frac{1}{v^{2}}+\frac{1}{\alpha_{\mathrm{gS}}}\right)^{2}}\right)>\left(\frac{1}{\frac{\kappa^{2}}{\alpha_{\pi \mathrm{S}}}+\frac{1}{v^{2}}+\frac{1}{\alpha_{\mathrm{gS}}}}\right),
$$

where the left-hand and right-hand sides represent the intratemporal losses under discretion and commitment, respectively. The additional intratemporal losses under discretion originate in the incentives of the government to employ inflation surprises as an instrument to alleviate tax distortions. The private sector correctly anticipates these incentives of the government to exploit nominal contracts. In this way, the interaction between the government, which cannot commit to a low-inflation policy, and the public, which correctly anticipates inflation, generates an inflation bias.

Wheras the intratemporal welfare loss due to discretion is relatively familiar from the literature, the second, intertemporal welfare loss is less well known. The following inequality indicates the suboptimality of the intertemporal allocation under discretion ${ }^{16}$

$$
\frac{(1+\rho)^{2}\left(\left(\beta_{\mathrm{D}}^{*}\right)^{2}+\beta_{\mathrm{S}}\right)}{\left(\beta_{\mathrm{D}}^{*}(1+\rho)+1\right)^{2}}>\frac{(1+\rho)^{2}\left(\left(\beta_{\mathrm{S}}^{*}\right)^{2}+\beta_{\mathrm{S}}\right)}{\left(\beta_{\mathrm{S}}^{*}(1+\rho)+1\right)^{2}},
$$

${ }^{15}$ Condition (4.2) is more likely to be met also if the policymaker is more patient, so that he attaches more weight to second period welfare losses. In that case, most of the intertemporal financing requirement is met in the first period so that a shift in the financing requirement from the second towards the first period exerts a relatively large impact on second-period policy outcomes.

${ }^{16}$ To derive this inequality, we use footnote 11. 
where $\beta_{\mathrm{D}}{ }^{*}$ is defined in Table 1 and evaluated at $\alpha^{\alpha}=\alpha_{s}$ and $\beta=\beta$, while ${ }_{\mathrm{S}} \beta$ is defined in (3.9). The intuition for the additional intertemporal welfare losses produced by discretion is as follows. From the perspective of a discretionary policymaker who sets policy in the first period, first-period expectations are pre-determined. The corresponding expectations in the second period, in contrast, still have to be determined and thus can be affected by (debt) policy. This induces the policymaker to rely relatively heavily on first-period financing, among other things in the form of unanticipated inflation, in order to reduce inflation expectations in the second period. However, in equilibrium, the private sector correctly anticipates the incentives of the government to use inflation surprises in the first period so as to build up assets in order to enhance the credibility of monetary policy in the second period. Hence, the discretionary equilibrium suffers from an asset bias associated with an excessive reliance on first-period sources of financing (if $\beta_{\mathrm{F}}=\beta_{\mathrm{S}}$ ). From society's point of view, inflation expectations are endogenous in not only the second period but also the first period. Hence, as under commitment, only smoothing of distortions and inter-temporal substitution effects (and not the credibility effect) should determine optimal debt policy.

\section{Optimal institutions}

To establish the second best, two additional distortions should offset, respectively, the intratemporal and the intertemporal misallocation of distortionary losses. As in the static version of the model, the optimal intratemporal trade-off is attained if

$$
\alpha_{\pi \mathrm{F}}=\alpha_{\pi \mathrm{F}}^{\mathrm{opt}}=\alpha_{\pi \mathrm{S}}(\kappa+1) / \kappa
$$

This value of $\alpha_{\pi \mathrm{F}}$ minimises the intratemporal welfare losses (i.e. the term in the first pair of square brackets in Table 2). The government has to be made more conservative than society (i.e. more inflation averse as measured by a higher value of $\alpha_{\pi \mathrm{F}}$ ) in order to offset the inflation bias due to discretion (see Rogoff, 1985).

In contrast to the static model and also in contrast to the case with decentralized decision making analyzed in Section 5 below, fiscal policy still does not face the correct incentives, even if the degree of inflation aversion is corrected according to (4.5). Intuitively, the adjustment of monetary preferences distorts intertemporal decisions. In particular, given their high inflation aversion (set according to (4.5)), the policymakers still perceive an inflationary bias in the second period, even though inflation is optimal from the point of view of society, which features a lower price stability weight than policymakers. Hence, they accumulate assets to bring inflation performance in the second period in line with their own preferences rather than those of society.

The intertemporal distortions can be eliminated in two ways. One is to adjust the subjective discount factor of the policymaker (for example, by an appropriate choice of the probability of dismissal after the first period). In particular, the second best is reached, if, in addition to (4.5), we set 


$$
\beta_{\mathrm{F}}^{\mathrm{opt}}=\beta_{\mathrm{S}}\left(\frac{\frac{\kappa^{2}}{\alpha_{\pi \mathrm{S}}}+\frac{1}{v^{2}}+\frac{1}{\alpha_{\mathrm{gS}}}}{\frac{\kappa(\kappa+1)}{\alpha_{\pi \mathrm{S}}}+\frac{1}{v^{2}}+\frac{1}{\alpha_{\mathrm{gS}}}}\right)<\beta_{\mathrm{S}} .
$$

The government thus must be made less patient than society. If governments are myopic (due to, e.g., short election cycles), this does not imply that the government necessarily has to be made less patient than it in fact is. In particular, (4.6) requires an increase in the degree of patience if governments are much less patient than society and if the optimal discount factor does not depart much from society's (so that $\beta_{\mathrm{F}}<\beta_{\mathrm{F}}$ opt). This latter condition is met if money holdings are small, the Philipscurve is relatively flat, and society attaches a high priority to price stability and a low priority to public spending. Under these conditions, the credibility effect is only small because policymakers do not perceive much of a need to enhance the credibility of future anti-inflation policies. These conditions for the credibility effect to be small are likely to be met in modern democracies, which tend to be characterized by small money holdings, large inflation aversion (Collins and Giavazzi, 1993), and impatient authorities due to short election cycles.

A second way to correct the intertemporal trade-off is to impose a debt target. The optimal debt target, which can be found by the minimisation of an expression similar to (3.8) (see Appendix C) can be chosen independently from the optimal inflation weight (4.5). Again, the optimal debt target is given by the optimal amount of debt $d_{1}$ under commitment (3.9). In combination with the adjustment of $\alpha_{\pi \mathrm{F}}$ to $\alpha_{\pi \mathrm{F}}^{\text {opt }}$ according to (4.5), the debt target yields the second best. $^{17}$

\section{Decentralized policymaking with an independent central bank}

In this section, policymaking is decentralized. In particular, the government takes as given the current inflation rate and selects only taxes, public spending and public debt. Monetary policy is delegated to an independent central banker, who is unable to commit and who selects the inflation rate, taking as given the policy choices of the government. In this case, the fiscal authority in the first period acts as a leader vis-à-vis the three players (including itself) in the second period. Hence, as we will see below, the fiscal authority may want to use debt strategically in the first period in order to affect expectations and policy decisions in the second period.

\section{Public debt accumulation}

${ }^{17}$ If $\beta_{\mathrm{F}}=\beta_{\mathrm{S}}$, (3.9) puts a limit on asset accumulation rather than debt accumulation as advocated in the Maastricht Treaty for an EMU or in the proposed balanced budget amendments in the United States. However, a debt ceiling may be desirable if $\beta_{\mathrm{F}}$ is much lower than $\boldsymbol{\beta}_{\mathrm{S}}$. 
A full derivation of the equilibrium is contained in Appendix D. As before, the government sets the optimal debt level $\mathrm{d}_{1}$ by equating the marginal benefit and the marginal cost from issuing more debt

$$
\left[\mathrm{K}_{1}+(1+\rho) \mathrm{d}_{0}-\mathrm{d}_{1}\right]=\beta_{\mathrm{F}}(1+\rho)\left(\mathrm{N}_{\mathrm{D}}{ }^{*} / \mathrm{N}_{\mathrm{D}}\right)\left[\mathrm{K}_{2}+(1+\rho) \mathrm{d}_{1}\right]
$$

where $\mathrm{N}_{\mathrm{D}}=\kappa / \alpha_{\pi \mathrm{M}}+1 / v^{2}+1 / \alpha_{\mathrm{gS}}$ and $\mathrm{N}_{\mathrm{D}}{ }^{*} \equiv \alpha_{\pi \mathrm{F}} / \alpha_{\pi \mathrm{M}}{ }^{2}+1 / v^{2}+1 / \alpha_{\mathrm{gS}}$. Debt accumulation is again characterized by the smoothing and intertemporal substitution effects. In particular, if $\alpha_{\pi \mathrm{r}} / \alpha_{\pi \mathrm{M}}=\kappa$ (and, hence, $\mathrm{N}_{\mathrm{D}}{ }^{*} / \mathrm{N}_{\mathrm{D}}=1$ ), debt accumulation coincides with that under centralized commitment.

As in the case of centralized discretion, however, a third effect impacts debt policy. This so-called strategic effect orginates in disagreement between the first-period fiscal authority and the second-period monetary authority about second-period inflation. This disagreement causes the fiscal authority in the first period to strategically employ debt policy in order to affect second-period monetary policy.

For example, if the government cares much less about inflation than the monetary authority does (so that $\alpha_{\pi \mathrm{I}} / \alpha_{\pi \mathrm{M}}<\mathrm{K}$ and, hence, $\mathrm{N}_{\mathrm{D}}{ }^{*} / \mathrm{N}_{\mathrm{D}}<1$, thereby reducing the effective discount factor of the fiscal authority, $\beta_{\mathrm{ND}}{ }^{*}=\beta_{\mathrm{F}}{ }^{*} \mathrm{~N}_{\mathrm{D}}{ }^{*} / \mathrm{N}_{\mathrm{D}}$, below $\beta^{*}$ ), the government strategically raises debt in the first period in order to encourage the central bank to raise inflation in the second period. ${ }^{18}$ Higher debt raises second-period inflation because the associated higher debt service requires higher taxes in the second period. This reduces second-period output, thereby tempting the central bank to boost output by the way of unanticipated inflation. ${ }^{19}$

If the fiscal authority attaches a sufficiently high priority to price stability (compared to that of the central bank), the fiscal authority may want to reduce rather than raise debt strategically. In particular, the government reduces debt strategically if the central bank is not conservative enough from the ex-ante perspective of the fiscal authority (i.e. $\alpha_{\pi \mathrm{I}} / \alpha_{\pi \mathrm{M}}>\mathrm{K}$ and, hence, $\mathrm{N}_{\mathrm{D}}{ }^{*} / \mathrm{N}_{\mathrm{D}}>1$ ) so that second-period monetary policy suffers from an inflation bias from that ex-ante perspective. In that case, as a substitute for a sufficiently conservative central bank, the government reduces public debt in order to establish the credibility of anti-inflation policies in the second period.

This suggests that the government accumulates more debt if a conservative, independent

18 These results on decentralized discretion contrast sharply with those on centralized discretion. In particular, Section 4 showed that with centralized discretion the government always reduces debt to affect future inflation expectations (see also Obstfeld, 1991a,b). With decentralized discretion, in contrast, the government may want to raise rather than reduce debt for this purpose.

19 The strategic use of debt in a dynamic model implies that the price stability weight of the government affects the equilibrium and, in particular, the inflation performance. In the static model, in contrast, the price stability weight of the government does not affect the decentralized equilibrium with discretion (see Beetsma and Bovenberg, 1995). 
central bank reduces the need to establish the credibility of anti-inflation policies. ${ }^{20}$ To explore this issue, we compare debt accumulation under decentralized and centralized discretion. An independent central bank (i.e. decentralized policymaking) yields more debt accumulation if and only if $\beta_{\mathrm{D}}{ }^{*}>\beta_{\mathrm{ND}}{ }^{*} \equiv \beta_{\mathrm{F}}(1+\rho) \mathrm{N}_{\mathrm{D}}{ }^{*} / \mathrm{N}_{\mathrm{D}}$ or $\mathrm{D}^{*} / \mathrm{D}>\mathrm{N}_{\mathrm{D}}{ }^{*} / \mathrm{N}_{\mathrm{D}}$. This condition reduces to (see Appendix E),

$$
\left(\frac{1}{v^{2}}+\frac{1}{\alpha_{\mathrm{gS}}}\right)\left(\frac{(\kappa+1)}{\alpha_{\pi \mathrm{F}}}+\frac{1}{\alpha_{\pi \mathrm{M}}}\left(\kappa-\frac{\alpha_{\pi \mathrm{F}}}{\alpha_{\pi \mathrm{M}}}\right)\right)+\left(\frac{\kappa(\kappa+1)}{\alpha_{\pi \mathrm{M}}}\right)\left(\frac{\kappa+1}{\alpha_{\pi \mathrm{F}}}-\frac{1}{\alpha_{\pi \mathrm{M}}}\right)>0 .
$$

This condition is certainly met if policymakers' preferences coincide with those of society. An independent central bank may lead to lower debt accumulation only if it is less conservative than a dependent central bank sharing the government's preferences (in particular if $\alpha_{\pi \mathrm{M}}<\alpha_{\pi \mathrm{I}} /(\kappa+1)$ ). In this peculiar case, the government reduces debt to make up for the lack of conservatism of the independent central bank.

\section{Inflation}

In a static model, a more conservative central bank unambiguously enhances price stability. In a dynamic model, the effects on long-term price stability are less clear because a more conservative central bank may lead to more debt accumulation, thereby increasing inflationary pressures in the long run. Indeed, an increase in $\alpha_{\pi \mathrm{M}}$ (for given $>0$ ) produces not only an intratemporal shift away from inflation towards higher taxes and lower public spending (as in the static model) but also an intertemporal shift in financing requirement. In particular, if $\alpha_{\pi \mathrm{M}}$ is not too high, an increase in $\alpha_{\pi M}$ reduces $\beta_{\mathbb{D}}{ }^{*}$, thereby shifting distortionary losses towards the second period and thus putting upward pressure on second-period inflation. Appendix $F$ finds that the intertemporal effect dominates the intratemporal effect, and, hence, results in a higher second-period inflation only for small values of $\alpha_{\pi \mathrm{M}}$. Accordingly, as an instrument to establish long-term price stability, a more conservative central bank is effective only if it is made conservative enough. Intuitively, if the central bank attaches a very high weight to price stability, the fiscal authority does not engage in the strategic accumulation of debt because it realises that the conservative central bank will barely raise second-period inflation in response to a higher second-period financing requirement. ${ }^{21}$

The result that, for relatively low values of $\alpha_{\pi \mathrm{M}}$, a more conservative central bank may raise long-run inflation is reminiscent of the well known unpleasant monetarist arithmetic (see Sargent and Wallace, 1981), which implies that a tighter short-run monetary policy may lead to higher

\footnotetext{
${ }^{20}$ The result that a more conservative central bank raises debt accumulation appears in other places in the literature (see, e.g., Tabellini, 1986).

21 Indeed, for high values of $\alpha_{\pi \mathrm{M}}$, a further increase $\operatorname{in}_{\pi} \alpha$ raise ${ }_{\mathrm{S}_{D}} \beta$, thereby increasing asset accumulation and thus reinforcing the downward pressure of the intratemporal effect of an increase in $\alpha_{\pi M}$ on second-period inflation. Appendix F establishes that second-period inflation is increasing in $\alpha_{\pi \mathrm{M}}$ for $\alpha_{\pi \mathrm{M}}<\alpha_{\pi \mathrm{M}}{ }^{*}$, decreasing in $\alpha_{\pi \mathrm{M}}$ for $\alpha_{\mathrm{TM}}>\alpha_{\mathrm{TM}}{ }^{*}$ and, hence, reaches a global maximum if $\alpha_{\mathrm{MM}}=\alpha_{\mathrm{MM}}{ }^{*}$, where ${ }_{\pi}{ }^{*}$ $\left\{\left[\beta_{\mathrm{S}}^{*}(1+\rho) \alpha_{\pi \mathrm{F}}\right] /\left[\left(1+\boldsymbol{\beta}_{\mathrm{S}}^{*}(1+\rho)\right)\left(1 / v^{2}+1 / \alpha_{\mathrm{gS}}\right)\right]\right\}^{1 / 2}$.
} 
inflation in the longer run. In contrast to Sargent and Wallace (1981), we derive this result as the time-consistent outcome of an explicitly formulated game between the fiscal and monetary authorities.

To explore this issue further, we compare the inflation performance under decentralized discretion with that under centralized commitment (see Section 3) under the assumptions that the policymakers share society's inflation aversion (i.e. $\alpha_{\pi \mathrm{M}}=\alpha_{\pi \mathrm{F}}=\alpha_{\pi \mathrm{S}}$ ) and that $\kappa<1$, which seems realistic for modern economies with efficient means of payment and hence low base money holdings. Under these assumptions, inflation is excessive under decentralized discretion (i.e. it exceeds the second-best level) in the static version of the model. As a direct consequence, the government strategically accumulates assets to reduce inflation in the second period. The associated shift in the financing requirement away from the second period may reverse the result from the static model that inflation is lowest under centralized commitment. In particular, second-period inflation is highest under centralized commitment if (see Appendix G)

$$
\left(\frac{\beta_{\mathrm{F}}^{*}(1+\rho)}{\beta_{\mathrm{F}}^{*}(1+\rho)+1}\right)\left(\frac{\kappa}{\alpha_{\pi \mathrm{S}}\left(1 / v^{2}+1 / \alpha_{\mathrm{gS}}\right)}\right)>1 .
$$

This inequality is met if the following conditions are met. First, the government should be patient, so that a large part of the intertemporal financing requirement must be met in first period. Accordingly, a small shift in financing requirements exerts a major impact on the second-period inflation rate. The second condition is that the Phillips curve be steep, so that the strategic asset accumulation is indeed effective in inducing the central bank to raise the second-period inflation rate. Finally, inflation should account for a relatively large share of the financing requirement so that a lower second-period financing requirement implies a substantial drop in inflation at that time. Small inflation aversion, a large preference weight for public spending, and large money holdings contribute to such a relatively large share of seigniorage. In this connection, inequality (5.3) suggests that higher second-period inflation under centralized commitment (i.e. unpleasant monetarist arithmetic) is unlikely to occur in modern economies with small money holdings.

\section{Welfare}

To interpret the welfare losses contained in Table 2, we continue to assume that the policymakers share society's inflation aversion (i.e. $\alpha_{\pi \mathrm{M}}=\alpha_{\pi \mathrm{F}}=\alpha_{\pi \mathrm{S}}$ ) and that $\kappa<1$. Accordingly, inflation is excessive not only under centralized discretion (see Section 4) but also under decentralized discretion. The reason is that the distortion due to discretion (i.e. the self-defeating incentive facing discretionary monetary policymakers to boost output through unanticipated inflation) dominates the distortion due to decentralization (i.e. an independent central bank ignoring the beneficial social role of inflation in generating additional seigniorage revenues (which depends on $\kappa)$ ).

Accordingly, just as under centralized discretion (see Section 4), the inability to commit 
under decentralized discretion results in two sources of additional welfare loss compared to the second best. The first source, the suboptimal intratemporal allocation of distortionary losses, stems from inflation being too high compared to the socially optimal inflation rate. The second source, the suboptimal intertemporal allocation of distortions, originates in the strategic use of the debt instrument. However, if the fiscal authority is myopic, the strategic effect (which reduces debt accumulation) offsets political distortions (which raise debt accumulation).

\section{Optimal institutions}

Letting the preferences of discretionary policymakers depart from societies' preferences may enhance welfare by offsetting the distortions associated with discretionary policymaking (see Rogoff, 1985). In particular, in the absence of political distortions (so that the government shares society's preferences), a necessary and sufficient condition for establishing the second best is that the price stability weight of the independent central bank is set according to ${ }^{22}$

$$
\alpha_{\pi \mathrm{M}}=\alpha_{\pi \mathrm{M}}^{\mathrm{opt}} \equiv \alpha_{\pi \mathrm{S}} / \kappa
$$

An optimally designed independent central bank thus results in an optimal allocation of distortions not only intra- but also intertertemporally. Intuitively, the incentive facing the first-period fiscal authority to use debt policy strategically originates in the inability to commit monetary policy in the second period. If this problem is removed by properly adjusting the preferences of the central bank, the fiscal authority no longer perceives any need to employ debt policy strategically in order to move second-period monetary policy closer to the social optimum. ${ }^{23}$ Indeed, correcting monetary policy preferences is a direct way to eliminate the distortions due to the inability to commit.

Decentralized decisionmaking with an independent central bank facilitates optimal institutional design. In particular, with an independent central bank, the preferences of the government do not need to diverge from society's preferences. With centralized discretionary policymaking (i.e. a dependent central bank), in contrast, the government should not only be more impatient and conservative than society but also should even be more conservative than the optimally designed independent central bank (see Section 4, in particular, compare (5.4) with (4.5)).

The presence of political distortions complicates the optimal institutional design. In this case, granting an independent central bank the proper degree of conservatism (i.e. setting $\alpha_{\pi M}$ according to (5.4)) is no longer sufficient for attaining the second-best. Intuitively, changing monetary institutions is not the most appropriate instrument to deal with imperfect fiscal institutions. Indeed, with political distortions involving the preferences of the fiscal authorities in

\footnotetext{
${ }^{22}$ This expression for the optimal degree of conservatism of an independent central bank coincides with the corresponding expression in the static model.

${ }^{23}$ The price stability weight of the central bank set according to (5.4) ensures that the effective discount rate $\beta_{\mathrm{ND}}{ }^{*}$ equals the corresponding rate of society $\boldsymbol{\beta}_{\mathrm{S}}{ }^{*}$.
} 
addition to distortions due to the inability to commit monetary policy, the second best can be established only by employing two instruments, each targetted at one of the distortions. In particular, the second best is established by, first, properly designing monetary institutions to address the distortions due to discretionary policymaking (i.e. setting $\alpha_{\pi \mathrm{M}}=\alpha_{\pi \mathrm{S}} / \kappa$ ) and, second, imposing an optimal debt target (given by (3.9)) $)^{24}$ to address the political distortions. This explains why the Delors Report (1989) on the design of monetary and fiscal institutions in the EMU emphasises the importance of debt ceilings as complements to a conservative, independent central bank.

To further explore the significance of debt ceilings, we investigate what happens if only monetary institutions can be designed optimally. ${ }^{25}$ In that case, the second best can not be attained. Moreover, monetary institutions can no longer be targetted only at ensuring the optimal inflation rate, because they have to bear also the burden of dealing with political distortions. Indeed, eliminating the inflationary bias of discretionary policymaking by properly adjusting the price stability weight of the central bank worsens fiscal distortions due to myopic fiscal policymakers.

To explore these complications in more detail, we first consider the case where the government shares society's inflation aversion, but is myopic $\left(\beta_{\mathrm{F}}<\beta_{\mathrm{S}}\right)$. In that case, the optimal price stability weight of the central bank, $\alpha_{\pi \mathrm{M}}$ opt , trades off inter- and intratemporal distortions and lies between the weight $\alpha_{\pi \mathrm{M}}^{\mathrm{E}}\left(0<\alpha_{\pi \mathrm{M}}{ }^{\mathrm{E}}<\alpha_{\pi \mathrm{S}} / \kappa\right)$ that minimizes the intertemporal loss factor and the weight $\alpha_{\pi \mathrm{S}} / \kappa$ that minimizes the intratemporal loss factor (see Appendix H1). Accordingly, the central bank should be made less conservative than in the case of a benevolent fiscal authority in order to encourage the myopic fiscal authority to restrain debt accumulation so as to enhance the credibility of monetary policy. In this way, the need to alleviate political distortions distracts monetary policy from its primary mission of ensuring price stability. This explains why central bankers are strong advocates of instruments dealing more directly with fiscal myopia, such as ceilings on fiscal debt in the context of the EMU.

We now turn to the case of a fiscal authority who shares society's time preference rate but who is opportunistic (i.e. $\alpha_{\pi \mathrm{F}}<\alpha_{\pi \mathrm{S}}$ ). ${ }^{26}$ In that case, whereas monetary distortions are eliminated (i.e. intratemporal losses are minimized) if $\alpha_{\pi \mathrm{M}}=\alpha \nless k$, fiscal distortions are taken away (i.e. intertemporal losses are minimized) if $\alpha_{\pi \mathrm{M}}=\alpha_{\pi \mathrm{f}} / \kappa$. The optimal degree of central bank conservatism trades off additional intra- and intertemporal losses. Whereas $\alpha_{\pi \mathrm{M}}^{\text {opt }}>\alpha_{\pi \mathrm{r}} / \kappa$, it cannot be ruled out that $\alpha_{\pi \mathrm{M}}^{\mathrm{opt}}>\alpha_{\pi \mathrm{S}} / \mathrm{k}$ (see Appendix H2). This can be illustrated with the special case where the fiscal

\footnotetext{
${ }^{24}$ The optimal debt target puts a limit on debt accumulation or asset accumulation, depending on whether $\alpha_{\pi \mathrm{F}} / \alpha_{\pi \mathrm{M}}<\kappa$ or $\alpha_{\pi \mathrm{F}} / \alpha_{\pi \mathrm{M}}>\mathrm{K}$ (if $\beta_{\mathrm{F}}=\beta_{\mathrm{S}}$ ), or whether $\beta_{\mathrm{F}}<\beta_{\mathrm{S}}$ or $\beta_{\mathrm{F}}>\beta_{\mathrm{S}}\left(\right.$ if $\left.\alpha_{\pi \mathrm{F}} / \alpha_{\pi \mathrm{M}}=\kappa\right)$.

${ }^{25}$ Indeed, compared to monetary institutions, fiscal institutions are much closer to the day-to-day political process. Hence, in practice, it may be impossible to deal with political distortions by imposing debt ceilings or by correcting the preferences of the government.

${ }^{26}$ Recall that in a static model the price stability weight of the government does not affect the equilibrium. Hence, in a static context the second best can be attained by setting the price stability weight of the independent central bank according to (5.4).
} 
authority does not care at all about inflation, i.e. $\alpha_{\pi \mathrm{F}}=0$. In that case, ${ }_{N} \beta{ }^{*}$ is monotonically increasing in $\alpha_{\pi \mathrm{M}}$, but never exceeds $\beta_{\mathrm{S}}{ }^{*}$ (at which value for $\beta_{\mathrm{D}}{ }^{*}$ the intertemporal component of welfare losses is minimal). Accordingly, whereas increasing the price stability weight of the central bank from $\alpha_{\pi \mathrm{M}}{ }^{\mathrm{opt}}=\alpha_{\pi \mathrm{S}} / \kappa$ does not produce any first-order effects on the intratemporal component of the welfare loss, it still yields first-order reductions in the intertemporal component of the welfare loss. This implies that $\alpha_{\pi \mathrm{M}}{ }^{\mathrm{opt}}>\alpha_{\pi \mathrm{s}} / \kappa$. Intuitively, the central bank needs to be made more conservative than in the second best in order to act as a counterweight against the extremely opportunistic fiscal authority.

\section{Conclusions}

This paper investigated how the strategic interaction between monetary and fiscal authorities impacts debt policy. If a centralized, benevolent policymaker sets all policy instruments, the inability to commit produces welfare losses that are due not only to the usual intratemporal inflation bias but also to excessive accumulation of assets. With monetary policy decentralized to an independent central bank, the conflict between this central bank and the government about future monetary policy induces the government to use debt strategically. In the absence of political distortions, a properly designed conservative, independent central bank is sufficient to establish the second best. With an opportunistic or myopic government, however, these monetary institutions need to be supplemented by an optimal debt target in order to attain the second best. If myopia in fiscal policy cannot be corrected by a debt target, a conservative central bank may be counterproductive in that it leads to excessive debt accumulation. This provides a rationale for the public debt criterion in the Maastricht Treaty as a supplement to an independent European Central Bank, which gives priority to price stability.

\section{References:}

Aghion, P. and P. Bolton (1989), 'Government Domestic Debt and Risk of Default: A PoliticalEconomic Model of the Strategic Role of Debt', in Dornbusch, R. and M. Draghi (eds.), Capital Markets and Debt Management.

Alesina, A. and G. Tabellini (1987), 'Rules and Discretion with Non-Coordinated Monetary and Fiscal Policies', Economic Inquiry, Vol.25, pp.619-30.

Alesina, A. and G. Tabellini (1990), 'A Positive Theory of Fiscal Deficits and Government Debt', Review of Economic Studies, Vol.57, pp.403-14.

Barro, R.J. (1979), 'On the Determination of the Public Debt', Journal of Political Economy, Vol.87, pp.940-71.

Barro, R.J. and D.B. Gordon (1983), 'Rules, Discretion and Reputation in a Model of Monetary Policy, Journal of Monetary Economics, Vol.12, pp.101-21.

Beetsma, R.M.W.J. and A.L. Bovenberg (1995), 'Designing Fiscal and Monetary Institutions in a Second-Best World', mimeo, DELTA and CentER.

Calvo, G.A. and P.E. Guidotti (1992), 'Optimal Maturity of Nominal Government Debt: An Infinite Horizon Model', International Economic Review, Vol.33, pp.895-919.

Calvo, G.A. and M. Obstfeld (1990), 'Time Consistency of Fiscal and Monetary Policy: A Comment', Econometrica, Vol.58, pp.1245-7. 
Chamley, C. (1986), 'Optimal Taxation of Capital Income in General Equilibrium with Infinite Lives", Econometrica, Vol.54, pp.607-22.

Collins, S.M. and F. Giavazzi (1993), 'Attitudes Towards Inflation and the Viability of Fixed Exchange Rates: Evidence from the EMS', in Bordo, M. and B. Eichengreen (eds.), A Retrospective on the Bretton Woods System, University of Chicago Press, Chicago.

Cukierman, A., Edwards, S. and G. Tabellini (1992), 'Seigniorage and Political Instability', American Economic Review, Vol.82, pp.537-55.

Debelle, G. (1993), 'Central Bank Independence: A Free Lunch?', mimeo, MIT.

Debelle, G. and S. Fischer (1994), 'How Independent Should a Central Bank Be?', mimeo, MIT.

Jensen, H. (1994), 'Loss of Monetary Discretion in a Simple Monetary Policy Game', Journal of Economic Dynamics and Control, Vol.18, pp.763-79.

Krichel, T., Levine, P. and J. Pearlman (1994), 'Fiscal and Monetary Policy in a Monetary Union: Credible Inflation Targets or Monetised Debt?', mimeo, University of Surrey.

Levine, P. (1993), 'Fiscal Policy Co-ordination under EMU and the Choice of Monetary Instrument', The Manchester School, Vol.41, pp.1-12, Supplement.

Levine, P. and A. Brociner (1994), 'Fiscal Policy Coordination and EMU', Journal of Economic Dynamics and Control, Vol.18, pp.699-729.

Levine, P. and J. Pearlman (1992), 'Fiscal and Monetary Policy under EMU: Credible Inflation Target or Unpleasant Monetarist Arithmetic?', CEPR Discussion Paper, No.701.

Lucas, R.E. and Nancy L. Stokey (1983), 'Optimal Fiscal and Monetary Policy in an Economy without Capital', Journal of Monetary Economics, Vol.12, pp.55-93.

Mankiw, N.G. (1987), 'The Optimal Collection of Seigniorage. Theory and Evidence', Journal of Monetary Economics, Vol.20, pp.327-341.

Obstfeld, M. (1991a), 'Dynamic Seigniorage Theory: An Exploration', CEPR Discussion Paper, No.519.

Obstfeld, M. (1991b), 'A Model of Currency Depreciation and the Debt-Inflation Spiral', Journal of Economic Dynamics and Control, Vol.15, pp.151-77.

Persson, M., Persson, T. and L.E.O. Svensson (1987), 'Time Consistency of Fiscal and Monetary Policy', Econometrica, Vol.55, pp.1419-31.

Persson, T. and L.E.O. Svensson (1984), 'Time-Consistent Policy and Government Cash-Flow', Journal of Monetary Economics, Vol.14, pp.365-74.

Persson, T. and L.E.O. Svensson (1989), 'Why a Stubborn Conservative Would Run a Deficit: Policy with Time-Inconsistent Preferences', Quarterly Journal of Economics, Vol.104, pp.325-45.

Rogoff, K. (1985), 'The Optimal Degree of Commitment to an Intermediate Monetary Target', Quartely Journal of Economics, Vol.99, pp.1169-89.

Sargent, T.J. and N. Wallace (1981), 'Some Unpleasant Monetarist Arithmetic', Federal Reserve Bank of Minneapolis Quarterly Review, pp.1-17.

Tabellini, G. (1986), 'Money, Debt and Deficits in a Dynamic Game', Journal of Economic Dynamics and Control, Vol.10, pp.427-42. 
Table 1: Policy outcomes under various regimes

\begin{tabular}{|c|c|c|c|c|}
\hline Policy variable: & \multicolumn{2}{|c|}{ first period $(r=C, D, N D)$} & \multicolumn{2}{|c|}{ second period $(r=C, D, N D)$} \\
\hline$\kappa \pi_{t}$ & \multicolumn{2}{|c|}{$\omega_{\pi \pi} \beta_{r}^{*} \delta_{r} F$} & \multicolumn{2}{|c|}{$\omega_{\pi r} \delta_{r} F$} \\
\hline$\tau_{t}+\tilde{x}_{t} / \nu$ & \multicolumn{2}{|c|}{$\omega_{\tau r} \beta_{r}^{*} \delta_{r} F$} & \multicolumn{2}{|c|}{$\omega_{\tau r} \delta_{r} \mathrm{~F}$} \\
\hline$\tilde{g}_{\mathrm{t}}-\mathrm{g}_{\mathrm{t}}$ & \multicolumn{2}{|c|}{$\omega_{\mathrm{gr}} \beta_{\mathrm{r}}^{*} \delta_{\mathrm{r}} \mathrm{F}$} & \multicolumn{2}{|c|}{$\omega_{\mathrm{gr}} \delta_{\mathrm{r}} \mathrm{F}$} \\
\hline $\mathrm{d}_{1}$ & \multicolumn{2}{|c|}{$\frac{\tilde{\mathrm{K}}_{1}+(1+\rho) \mathrm{d}_{0}-\tilde{\mathrm{K}}_{2}+\left(1-\beta_{\mathrm{r}}^{*}\right) \tilde{\mathrm{K}}_{2}}{\beta_{\mathrm{r}}^{*}(1+\rho)+1}$} & \multicolumn{2}{|c|}{ N.A. } \\
\hline Regime (r) & $\omega_{\pi r}$ & $\omega_{\tau r}$ & $\omega_{\mathrm{gr}}$ & $\beta_{r}^{*}$ \\
\hline $\mathrm{C}$ & $\frac{\kappa^{2} / \alpha_{\pi \mathrm{F}}}{\mathrm{P}}$ & $\frac{1 / v^{2}}{\mathrm{P}}$ & $\frac{1 / \alpha_{g S}}{P}$ & $\beta_{\mathrm{C}}^{*} \equiv \beta_{\mathrm{F}}^{*}$ \\
\hline D & $\frac{\kappa(\kappa+1) / \alpha_{\pi \mathrm{F}}}{\mathrm{D}}$ & $\frac{1 / v^{2}}{\mathrm{D}}$ & $\frac{1 / \alpha_{\mathrm{gS}}}{\mathrm{D}}$ & $\beta_{\mathrm{D}}^{*} \equiv \beta_{\mathrm{F}}^{*} \mathrm{D}^{*} / \mathrm{D}$ \\
\hline ND & $\frac{\kappa / \alpha_{\pi M}}{N_{D}}$ & $\frac{1 / v^{2}}{N_{D}}$ & $\frac{1 / \alpha_{g S}}{N_{D}}$ & $\beta_{\mathrm{ND}}^{*} \equiv \beta_{\mathrm{F}}^{*} \mathrm{~N}_{\mathrm{D}}^{*} / \mathrm{N}_{\mathrm{D}}$ \\
\hline
\end{tabular}

Note: 1. Subscript $\mathrm{r}(=\mathrm{C}, \mathrm{D}$ or $\mathrm{ND})$ indicates the policy regime: $\mathrm{C}=$ centralized commitment, $\mathrm{D}=$ centralized discretion, ND $=$ Nash discretion .

2. $\quad$ N.A. $=$ not applicable.

3. Note that $\omega_{\pi \mathrm{r}}+\omega_{\tau \mathrm{rr}}+\omega_{\mathrm{gr}}=1$, for $\mathrm{r}=\mathrm{C}, \mathrm{D}$ or ND.

4. $\quad \beta_{\mathrm{F}}{ }^{*}=\beta_{\mathrm{F}}(1+\rho), \mathrm{F} \equiv \mathrm{K}_{1}+(1+\rho) \mathrm{d}_{0}+\mathrm{K}_{2} /(1+\rho), \mathrm{K}_{\mathrm{t}}=\tilde{\mathrm{g}}_{\mathrm{t}}+\tilde{\mathrm{x}}_{\mathrm{t}} / \nu$,

$\delta_{\mathrm{r}} \equiv(1+\rho) /\left[\beta_{\mathrm{r}}{ }^{*}(1+\rho)+1\right], \mathrm{P} \equiv \kappa^{2} / \alpha_{\pi \mathrm{F}}+1 / v^{2}+1 / \alpha_{\mathrm{gS}}, \mathrm{D} \equiv \kappa(\kappa+1) / \alpha_{\pi \mathrm{F}}+1 / v^{2}+1 / \alpha_{\mathrm{gS}}$,

$\mathrm{D}^{*} \equiv(\kappa+1)^{2} / \alpha_{\pi \mathrm{F}}+1 / v^{2}+1 / \alpha_{\mathrm{gS}}, \mathrm{N}_{\mathrm{D}} \equiv \kappa / \alpha_{\pi \mathrm{M}}+1 / v^{2}+1 / \alpha_{\mathrm{gS}}$,

$\mathrm{N}_{\mathrm{D}}{ }^{*} \equiv \alpha_{\pi \mathrm{I}} / \alpha_{\pi \mathrm{M}}{ }^{2}+1 / \nu^{2}+1 / \alpha_{\mathrm{gS}}$. 
Table 2: Welfare losses under various regimes

\begin{tabular}{|c|c|c|}
\hline $\begin{array}{l}\text { Policy } \\
\text { regime: }\end{array}$ & welfare loss: & optimal preferences: \\
\hline $\mathrm{C}$ & $\left(\frac{\frac{\kappa^{2} \alpha_{\pi \mathrm{S}}}{\alpha_{\pi \mathrm{F}}^{2}}+\frac{1}{v^{2}}+\frac{1}{\alpha_{\mathrm{gS}}}}{2 \mathrm{P}^{2}}\right)\left[\delta_{\mathrm{C}}^{2}\left(\left(\beta_{\mathrm{F}}^{*}\right)^{2}+\beta_{\mathrm{S}}\right)\right] \tilde{\mathrm{F}}^{2}$ & $\beta_{\mathrm{F}}=\beta_{\mathrm{S}}, \alpha_{\pi \mathrm{F}}=\alpha_{\pi \mathrm{S}}$ \\
\hline D & $\left.\frac{\frac{(\kappa+1)^{2} \alpha_{\pi \mathrm{S}}}{\alpha_{\pi \mathrm{F}}^{2}}+\frac{1}{v^{2}}+\frac{1}{\alpha_{\mathrm{gS}}}}{2 \mathrm{D}^{2}}\right)\left[\delta_{\mathrm{D}}^{2}\left(\left(\beta_{\mathrm{D}}^{*}\right)^{2}+\beta_{\mathrm{S}}\right)\right] \tilde{\mathrm{F}}^{2}$ & $\begin{array}{c}\alpha_{\pi \mathrm{F}}=\alpha_{\pi \mathrm{S}}(\kappa+1) / \kappa \\
\beta_{\mathrm{F}}=\beta_{\mathrm{S}}\left(\begin{array}{c}\frac{\kappa^{2}}{\alpha_{\pi \mathrm{S}}}+\frac{1}{v^{2}}+\frac{1}{\alpha_{\mathrm{gS}}} \\
\frac{\kappa(\kappa+1)}{\alpha_{\pi \mathrm{S}}}+\frac{1}{v^{2}}+\frac{1}{\alpha_{\mathrm{gS}}}\end{array}\right)\end{array}$ \\
\hline ND & $\left(\frac{\frac{\alpha_{\pi \mathrm{S}}}{\alpha_{\pi \mathrm{M}}^{2}}+\frac{1}{v^{2}}+\frac{1}{\alpha_{\mathrm{gS}}}}{2 \mathrm{~N}_{\mathrm{D}}^{2}}\right)\left[\delta_{\mathrm{ND}}^{2}\left(\left(\beta_{\mathrm{ND}}^{*}\right)^{2}+\beta_{\mathrm{S}}\right)\right] \tilde{\mathrm{F}}^{2}$ & $\beta_{\mathrm{F}}=\beta_{\mathrm{S}}, \alpha_{\pi \mathrm{M}}=\alpha_{\pi \mathrm{S}} / \kappa$ \\
\hline
\end{tabular}

Note: For definitions, see Table 1. 


\section{Technical appendices}

A: Derivation of equilibrium policies under centralized commitment.

The equilibrium is derived by working back in time and solving for the optimal policies given the current value of the state variable (public debt) and given that future policies are optimally selected.

Substitute (2.1) into (2.3) (for $t=2$ ) and impose $\pi_{2}{ }^{e}=\pi_{2}$, so that the second-period Lagrangian of the fiscal authority can be written as,

$$
\mathfrak{L}=1 / 2\left[\alpha_{\pi \mathrm{F}} \pi_{2}^{2}+\left(v \tau_{2}+\tilde{\mathrm{x}}_{2}\right)^{2}+\alpha_{\mathrm{gS}}\left(\mathrm{g}_{2}-\tilde{\mathrm{g}}_{2}\right)^{2}\right]+\lambda_{2}\left[\mathrm{~g}_{2}+(1+\rho) \mathrm{d}_{1}-\tau_{2}-\kappa \pi_{2}\right]
$$

where $\lambda_{2}$ is the Lagrange multiplier associated with the government budget constraint in the second period. The first order conditions (given the linear-quadratic specification of the problem, the first order conditions are necessary and sufficient for the optimum) for $\pi_{2}, \tau_{2}$ and $g_{2}$ are given by, respectively,

$$
\begin{gathered}
\alpha_{\pi \mathrm{F}} \pi_{2}=\lambda_{2} \kappa, \\
v\left(v \tau_{2}+\tilde{\mathrm{x}}_{2}\right)=\lambda_{2}, \\
\alpha_{\mathrm{gs}}\left(\tilde{\mathrm{g}}_{2}-\mathrm{g}_{2}\right)=\lambda_{2},
\end{gathered}
$$

Eliminate $\lambda_{2}$ from the system (A.2)-(A.4) to obtain:

$$
\begin{aligned}
& \pi_{2}=\left(\kappa^{2} v^{2} / \alpha_{\pi \mathrm{F}}\right)\left(\tau_{2}+\tilde{x}_{2} / v\right), \\
& \tilde{\mathrm{g}}_{2}-\mathrm{g}_{2}=\left(v^{2} / \alpha_{\mathrm{gS}}\right)\left(\tau_{2}+\tilde{x}_{2} / v\right),
\end{aligned}
$$

Combine (A.5) and (A.6) with the government financing requirement (2.7) for period 2, to obtain the secondperiod policy outcomes for given value of $d_{1}$ :

$$
\begin{gathered}
\pi_{2}=\left(\frac{\kappa / \alpha}{\mathrm{P} F}\right)\left(\tilde{\mathrm{K}}_{2}+(1+\rho) \mathrm{d}_{1}\right), \\
\tau_{2}+\tilde{\mathrm{X}}_{2} / \nu=\left(\frac{1 / v^{2}}{\mathrm{P}}\right)\left(\tilde{\mathrm{K}}_{2}+(1+\rho) \mathrm{d}_{1}\right), \\
\tilde{\mathrm{g}}_{2}-\mathrm{g}_{2}=\left(\frac{1 / \alpha_{\mathrm{gS}}}{\mathrm{P}}\right)\left(\tilde{\mathrm{K}}_{2}+(1+\rho) \mathrm{d}_{1}\right),
\end{gathered}
$$

where $\mathrm{P} \equiv \kappa^{2} / \alpha_{\pi \mathrm{F}}+1 / v^{2}+1 / \alpha_{\mathrm{gs}}$. Substitution of (A.1)-(A.3) into the fiscal authority's welfare loss function (and imposing $\left.\pi_{2}{ }^{e}=\pi_{2}\right)$, yields a second period welfare loss of $1 / 2 \mathrm{P}^{-1}\left[\mathrm{~K}_{2}+(1+\rho) d_{1}\right]^{2}$.

Therefore, if we substitute (2.1) into (2.3) (for $t=1)$ and impose $\pi_{1}{ }^{e}=\pi_{1}$, the first-period Lagrangian of the fiscal authority can be written as,

$$
\mathfrak{L}=1 / 2\left[\alpha_{\pi \mathrm{F}} \pi_{1}^{2}+\left(v \tau_{1}+\tilde{\mathrm{x}}_{1}\right)^{2}+\alpha_{\mathrm{gS}}\left(\mathrm{g}_{1}-\tilde{\mathrm{g}}_{1}\right)^{2}\right]+1 / 2 \beta_{\mathrm{F}} \mathrm{P}^{-1}\left[\mathrm{~K}_{2}+(1+\rho) \mathrm{d}_{1}\right]^{2}+
$$




$$
\lambda_{1}\left[g_{1}+(1+\rho) d_{0}-\tau_{1}-\kappa \pi_{1}-d_{1}\right]
$$

where $\lambda_{1}$ is the Lagrange multiplier associated with the government budget constraint in the first period. The first order conditions for $\pi_{1}, \tau_{1}, g_{1}$ and $d_{1}$ are given by, respectively,

$$
\begin{gathered}
\alpha_{\pi \mathrm{F}} \pi_{1}=\lambda_{1} \kappa, \\
v\left(v \tau_{1}+\tilde{\mathrm{x}}_{1}\right)=\lambda_{1}, \\
\alpha_{\mathrm{gS}}\left(\tilde{\mathrm{g}}_{1}-\mathrm{g}_{1}\right)=\lambda_{1}, \\
\beta_{\mathrm{F}} \mathrm{P}^{-1}\left[\mathrm{~K}_{2}+(1+\rho) \mathrm{d}_{1}\right](1+\rho)=\lambda_{1} .
\end{gathered}
$$

Combine (A.11)-(A.13) with the government financing requirement (2.7) for period 1, to yield

$$
v\left(v \tau_{1}+\tilde{x}_{1}\right)=\mathrm{P}^{-1}\left[\mathrm{~K}_{1}+(1+\rho) \mathrm{d}_{0}-\mathrm{d}_{1}\right] .
$$

Combine (A.12), (A.14) and (A.15) to give

$$
\left[\mathrm{K}_{1}+(1+\rho) \mathrm{d}_{0}-\mathrm{d}_{1}\right]=\beta_{\mathrm{F}}(1+\rho)\left[\mathrm{K}_{2}+(1+\rho) \mathrm{d}_{1}\right]
$$

Equation (A.16) can be rewritten as,

$$
\mathrm{d}_{1}=\left[\boldsymbol{\beta}_{\mathrm{F}}{ }^{*}(1+\rho)+1\right]^{-1}\left\{\left[\mathrm{~K}_{1}+(1+\rho) \mathrm{d}_{0}-\mathrm{K}_{2}\right]+\left(1-\boldsymbol{\beta}_{\mathrm{F}}{ }^{*}\right) \mathrm{K}_{2}\right\} \text {, where } \boldsymbol{\beta}_{\mathrm{F}}{ }^{*} \equiv \boldsymbol{\beta}_{\mathrm{F}}(1+\rho) \text {. }
$$

Substitute (A.17) into (A.15) and rewrite to give the equilibrium tax rate in period 1,

$$
\tau_{1}+\tilde{\mathrm{X}}_{1} / \nu=\left(\frac{1 / \nu^{2}}{\mathrm{P}}\right)\left(\frac{\beta_{\mathrm{F}}^{*}(1+\rho)\left(\tilde{\mathrm{K}}_{1}+(1+\rho) \mathrm{d}_{0}\right)+\beta_{\mathrm{F}}^{*} \tilde{\mathrm{K}}_{2}}{\beta_{\mathrm{F}}^{*}(1+\rho)+1}\right) .
$$

Similarly, substitute (A.17) into (A.8) and rewrite to give the equilibrium tax rate in period 2,

$$
\tau_{2}+\tilde{\mathrm{X}}_{2} / v=\left(\frac{1 / v^{2}}{\mathrm{P}}\right)\left(\frac{(1+\rho)\left(\tilde{\mathrm{K}}_{1}+(1+\rho) \mathrm{d}_{0}\right)+\tilde{\mathrm{K}}_{2}}{\beta_{\mathrm{F}}^{*}(1+\rho)+1}\right) .
$$

It can be easily verified that (A.18) and (A.19) coincide with the corresponding "compressed" expressions presented in Table 1. The expressions for the other policy variables can be found in a similar way using the first-order conditions for the policy instruments in the first and the second period.

\section{B: Proof of (4.2), the condition under which second period inflation is} lower with centralized discretion than with centralized commitment.

Using Table 1 and the assumption that the authorities' price stability weights coincide with society's, we find that second-period inflation is lower with centralized discretion than with centralized commitment if and only if, 


$$
\begin{gathered}
\left(\frac{\kappa / \alpha_{\pi \mathrm{S}}}{\mathrm{P}}\right)\left(\frac{(1+\rho) \tilde{\mathrm{F}}}{\beta_{\mathrm{F}}^{*}(1+\rho)+1}\right)>\left(\frac{(\kappa+1) / \alpha_{\pi \mathrm{S}}}{\mathrm{D}}\right)\left(\frac{(1+\rho) \tilde{\mathrm{F}}}{\beta_{\mathrm{F}}^{*}\left(\mathrm{D}^{*} / \mathrm{D}\right)(1+\rho)+1}\right) \Leftrightarrow \\
\beta_{\mathrm{F}}^{*}(1+\rho)\left(\kappa \mathrm{D}^{*}-(\kappa+1) \mathrm{P}\right)+(\kappa \mathrm{D}-(\kappa+1) \mathrm{P})>0 \Leftrightarrow \\
\beta_{\mathrm{F}}^{*}(1+\rho)\left(\frac{\kappa(\kappa+1)}{\alpha_{\pi \mathrm{S}}}-\left(\frac{1}{v^{2}}+\frac{1}{\alpha_{\mathrm{gS}}}\right)\right)-\left(\frac{1}{v^{2}}+\frac{1}{\alpha_{\mathrm{gS}}}\right)>0 \Leftrightarrow \\
\beta_{\mathrm{F}}^{*}(1+\rho)\left(\frac{\kappa(\kappa+1)}{\alpha_{\pi \mathrm{S}}}\right)>\left(\beta_{\mathrm{F}}^{*}(1+\rho)+1\right)\left(\frac{1}{v^{2}}+\frac{1}{\alpha_{\mathrm{gS}}}\right) .
\end{gathered}
$$

Divide both sides by the right hand side of (B.1) to yield (4.2).

\section{C: Derivation optimal debt target under centralized discretion.}

The optimal debt target follows immediately from the minimisation (over $\mathrm{d}_{1}$ ) of

$$
\left(\frac{\frac{(\kappa+1)^{2} \alpha_{\pi \mathrm{S}}}{\alpha_{\pi \mathrm{F}}^{2}}+\frac{1}{v^{2}}+\frac{1}{\alpha_{\mathrm{gS}}}}{2 \mathrm{D}^{2}}\right)\left(\left(\tilde{\mathrm{K}}_{1}+(1+\rho) \mathrm{d}_{0}-\hat{\mathrm{d}}_{1}\right)^{2}+\beta_{\mathrm{S}}\left(\tilde{\mathrm{K}}_{2}+(1+\rho) \hat{\mathrm{d}}_{1}\right)^{2}\right) .
$$

D: Derivation of the equilibrium policies under decentralized discretion.

The central bank and the fiscal authority play a Nash game in the first and second period. The central bank chooses the inflation rate taking as given the fiscal authority's policy choices and taking as given the expected inflation rate. The fiscal authority selects the $\tau_{2}$ and $g_{2}$ in period 2, taking as given $\tau_{2}$ and $\tau_{2}{ }^{e}$, and $\tau_{1}, g_{1}$ and $d_{1}$ in period 1 , taking as given $\pi_{1}$ and $\pi_{1}{ }^{e}$.

In period 2 the central bank selects $\pi_{2}$ to minimize the expression $1 / 2\left[\alpha_{\pi \mathrm{M}} \pi_{2}{ }^{2}+\left(v\left(\pi_{2}-\pi_{2}{ }^{\mathrm{e}}-\tau_{2}\right)-\tilde{\mathrm{x}}_{2}\right)^{2}+\alpha_{\mathrm{gS}}\left(\mathrm{g}_{2}{ }^{-}\right.\right.$ $\left.\tilde{\mathrm{g}}_{2}\right)^{2}$. The first-order condition yields the central bank's reaction function,

$$
\pi_{2}=v^{2}\left(\alpha_{\pi M}+v^{2}\right)^{-1}\left(\pi_{2}^{e}+\tau_{2}+\tilde{\mathbf{x}}_{2}\right)
$$

The second period Lagrangian of the fiscal authority is,

$$
\mathfrak{E}=1 / 2\left[\alpha_{\pi \mathrm{F}} \pi_{2}^{2}+\left(v\left(\pi_{2}-\pi_{2}{ }^{\mathrm{e}}-\tau_{2}\right)-\tilde{\mathrm{x}}_{2}\right)^{2}+\alpha_{\mathrm{gs}}\left(\mathrm{g}_{2}-\tilde{\mathrm{g}}_{2}\right)^{2}\right]+\lambda_{2}\left[\mathrm{~g}_{2}+(1+\rho) \mathrm{d}_{1}-\tau_{2}-\kappa \pi_{2}\right]
$$

where $\lambda_{2}$ is the Lagrange multiplier associated with the government budget constraint in period 2 . The first order conditions for $\tau_{2}$ and $g_{2}$ are, respectively,

$$
-v\left(v\left(\pi_{2}-\pi_{2}^{e}-\tau_{2}\right)-\tilde{x}_{2}\right)=\lambda_{2}
$$




$$
\alpha_{\mathrm{gs}}\left(\tilde{\mathrm{g}}_{2}-\mathrm{g}_{2}\right)=\lambda_{2}
$$

Impose rationality of expectations $\pi_{2}{ }^{\mathrm{e}}=\pi_{2}$ upon (D.1) and (D.3) and combine the resulting expressions and (D.4) with the government financing requirement (2.7) for period 2, to yield

$$
v\left(v \tau_{2}+\tilde{\mathbf{x}}_{2}\right)=\mathrm{N}_{\mathrm{D}}^{-1}\left[\mathrm{~K}_{2}+(1+\rho) \mathrm{d}_{2}\right]
$$

where $\mathrm{N}_{\mathrm{D}} \equiv \mathrm{K} / \alpha_{\pi \mathrm{M}}+1 / v^{2}+1 / \alpha_{\mathrm{gg}}$. Hence, using (D.1) $\left(\pi_{2}{ }^{\mathrm{e}}=\pi_{2}\right)$, (D.3) and (D.4), we arrive at,

$$
\begin{gathered}
\pi_{2}=\left(\frac{1 / \alpha_{\pi \mathrm{M}}}{\mathrm{N}_{\mathrm{D}}}\right)\left(\tilde{\mathrm{K}}_{2}+(1+\rho) \mathrm{d}_{1}\right), \\
\tau_{2}+\tilde{\mathrm{X}}_{2} / v=\left(\frac{1 / \nu^{2}}{\mathrm{~N}_{\mathrm{D}}}\right)\left(\tilde{\mathrm{K}}_{2}+(1+\rho) \mathrm{d}_{1}\right), \\
\tilde{\mathrm{g}}_{2}-\mathrm{g}_{2}=\left(\frac{1 / \alpha_{\mathrm{gS}}}{\mathrm{N}_{\mathrm{D}}}\right)\left(\tilde{\mathrm{K}}_{2}+(1+\rho) \mathrm{d}_{1}\right),
\end{gathered}
$$

Substitution of (D.6)-(D.8) into the fiscal authority's welfare loss function yields a second period welfare loss of $1 / 2\left(\mathrm{~N}_{\mathrm{D}}{ }^{*} / \mathrm{N}_{\mathrm{D}}{ }^{2}\right)\left[\mathrm{K}_{2}+(1+\rho) \mathrm{d}_{1}\right]^{2}$, where $\mathrm{N}_{\mathrm{D}}{ }^{*} \equiv \alpha_{\pi \mathrm{F}} / \alpha_{\pi \mathrm{M}}{ }^{2}+1 / v^{2}+1 / \alpha_{\mathrm{gS}}$.

In the first period, the central bank selects $\pi_{1}$ to minimize the expression $1 / 2\left[g_{f}{ }_{1} \pi^{2}+\left(v(\pi)-{ }_{1}{ }^{e}{ }^{e} \tau\right)\right.$ $\left.\left.\tilde{\mathrm{x}}_{1}\right)^{2}+\alpha_{\mathrm{gs}}\left(\mathrm{g}_{1}-\tilde{\mathrm{g}}_{1}\right)^{2}\right]$. The first-order condition yields the central bank's reaction function,

$$
\pi_{1}=v^{2}\left(\alpha_{\pi M}+v^{2}\right)^{-1}\left(\pi_{1}{ }^{e}+\tau_{1}+\tilde{x}_{1}\right)
$$

The first-period Lagrangian of the fiscal authority is,

$$
\begin{gathered}
£=1 / 2\left[\alpha_{\pi \mathrm{F}} \pi_{1}{ }^{2}+\left(v\left(\pi_{1}-\pi_{1}{ }^{\mathrm{e}}-\tau_{1}\right)-\tilde{\mathrm{x}}_{1}\right)^{2}+\alpha_{\mathrm{gs}}\left(\mathrm{g}_{1}-\tilde{\mathrm{g}}_{1}\right)^{2}\right]+1 / 2 \beta_{\mathrm{F}}\left(\mathrm{N}_{\mathrm{D}}{ }^{*} / \mathrm{N}_{\mathrm{D}}{ }^{2}\right)\left[\mathrm{K}_{2}+(1+\rho) \mathrm{d}_{1}\right]^{2}+ \\
\lambda_{1}\left[\mathrm{~g}_{1}+(1+\rho) \mathrm{d}_{0}-\tau_{1}-\kappa \pi_{1}-\mathrm{d}_{1}\right],
\end{gathered}
$$

where $\lambda_{1}$ is the Lagrange multiplier associated with the government budget constraint in period 1 . The first order conditions for $\tau_{1}, g_{1}$ and $d_{1}$ are given by, respectively,

$$
\begin{gathered}
-v\left(v\left(\pi_{1}-\pi_{1}{ }^{\mathrm{e}}-\tau_{1}\right)-\tilde{\mathrm{x}}_{1}\right)=\lambda_{1}, \\
\alpha_{\mathrm{gs}}\left(\tilde{\mathrm{g}}_{1}-\mathrm{g}_{1}\right)=\lambda_{1}, \\
\beta_{\mathrm{F}}\left(\mathrm{N}_{\mathrm{D}}{ }^{*} / \mathrm{N}_{\mathrm{D}}{ }^{2}\right)\left[\mathrm{K}_{2}+(1+\rho) \mathrm{d}_{1}\right](1+\rho)=\lambda_{1} .
\end{gathered}
$$

Impose rationality of expectations $\pi_{1}{ }^{e}=\pi_{1}$ upon (D.9) and (D.11) and combine the resulting expressions and (D.12) with the government financing requirement (2.7) for period 1, to yield

$$
v\left(v \tau_{1}+\tilde{x}_{1}\right)=N_{D}^{-1}\left[K_{1}+(1+\rho) d_{0}-d_{1}\right] .
$$


Impose rational expectations $\left(\pi_{1}{ }^{e}=\pi_{1}\right)$ on (D.11) and substitute (D.14) into the resulting expression for (D.11) to yield $\mathrm{N}_{\mathrm{D}}^{-1}\left[\mathrm{~K}_{1}+(1+\rho) \mathrm{d}_{0}-\mathrm{d}_{1}\right]=\lambda_{1}$. This can be substituted into (D.13) to give

$$
\left[\mathrm{K}_{1}+(1+\rho) \mathrm{d}_{0}-\mathrm{d}_{1}\right]=\beta_{\mathrm{F}}(1+\rho)\left(\mathrm{N}_{\mathrm{D}}{ }^{*} / \mathrm{N}_{\mathrm{D}}\right)\left[\mathrm{K}_{2}+(1+\rho) \mathrm{d}_{1}\right],
$$

Equation (D.15) can be rewritten as,

$$
\mathrm{d}_{1}=\left[\boldsymbol{\beta}_{\mathrm{ND}}{ }^{*}(1+\rho)+1\right]^{-1}\left\{\left[\mathrm{~K}_{1}+(1+\rho) \mathrm{d}_{0}-\mathrm{K}_{2}\right]+\left(1-\beta_{\mathrm{ND}}{ }^{*}\right) \mathrm{K}_{2}\right\} \text {, where } \boldsymbol{\beta}_{\mathrm{ND}}{ }^{*} \equiv \boldsymbol{\beta}_{\mathrm{F}}{ }^{*}\left(\mathrm{~N}_{\mathrm{D}}{ }^{*} / \mathrm{N}_{\mathrm{D}}\right) \text {. }
$$

Substitute (D.16) into (D.14) and rewrite to give the equilibrium tax rate in period 1,

$$
\tau_{1}+\tilde{\mathrm{X}}_{1} / \nu=\left(\frac{1 / v^{2}}{\mathrm{~N}_{\mathrm{D}}}\right)\left(\frac{\beta_{\mathrm{ND}}^{*}(1+\rho)\left(\tilde{\mathrm{K}}_{1}+(1+\rho) \mathrm{d}_{0}\right)+\beta_{\mathrm{ND}}^{*} \tilde{\mathrm{K}}_{2}}{\beta_{\mathrm{ND}}^{*}(1+\rho)+1}\right) .
$$

Similarly, substitute (D.16) into (D.7) and rewrite to give,

$$
\tau_{2}+\tilde{\mathrm{X}}_{2} / v=\left(\frac{1 / v^{2}}{\mathrm{~N}_{\mathrm{D}}}\right)\left(\frac{(1+\rho)\left(\tilde{\mathrm{K}}_{1}+(1+\rho) \mathrm{d}_{0}\right)+\tilde{\mathrm{K}}_{2}}{\beta_{\mathrm{ND}}^{*}(1+\rho)+1}\right)
$$

It can be easily verified that (D.17) and (D.18) coincide with the corresponding "compressed" expressions presented in Table 1. The expressions for the other policy variables can be found in a similar wayu using the first-order conditions and the central bank's reaction functions in the first and second period.

\section{E: Proof of (5.2), the condition under which centralized discretion leads to less debt accumulation than decentralized discretion.}

Note that debt accumulation is decreasing in the "effective discount factor", i.e. in $\beta_{\mathrm{D}}{ }^{*}$ in the case of centralized discretion and in $\beta_{\mathrm{ND}}{ }^{*}$ in the case of decentralized discretion. Hence, centralized discretion leads to less debt accumulation than decentralized discretion if and only if $D^{*} / D>N_{D}{ }^{*} / N_{D}$. This is equivalent to

$$
\left(\frac{(\kappa+1)^{2}}{\alpha_{\pi \mathrm{F}}}+\frac{1}{v^{2}}+\frac{1}{\alpha_{\mathrm{gS}}}\right)\left(\frac{\kappa}{\alpha_{\pi \mathrm{M}}}+\frac{1}{v^{2}}+\frac{1}{\alpha_{\mathrm{gS}}}\right)>\left(\frac{\kappa(\kappa+1)}{\alpha_{\pi \mathrm{F}}}+\frac{1}{v^{2}}+\frac{1}{\alpha_{\mathrm{gS}}}\right)\left(\frac{\alpha_{\pi \mathrm{F}}}{\alpha_{\pi \mathrm{M}}^{2}}+\frac{1}{v^{2}}+\frac{1}{\alpha_{\mathrm{gS}}}\right) .
$$

Working out the products (treating $\left(1 / v^{2}+1 / \alpha_{g g}\right)$ as a single term), cancelling the term $\left(17 v+1 / \mathrm{g}_{\mathrm{g}}{ }^{2}\right)$ on both sides, bringing all terms on the right hand side to the left hand side and rearranging yields (5.2):

$$
\left(\frac{1}{v^{2}}+\frac{1}{\alpha_{\mathrm{gS}}}\right)\left(\frac{(\kappa+1)}{\alpha_{\pi \mathrm{F}}}+\frac{1}{\alpha_{\pi \mathrm{M}}}\left(\kappa-\frac{\alpha_{\pi \mathrm{F}}}{\alpha_{\pi \mathrm{M}}}\right)\right)+\left(\frac{\kappa(\kappa+1)}{\alpha_{\pi \mathrm{M}}}\right)\left(\frac{\kappa+1}{\alpha_{\pi \mathrm{F}}}-\frac{1}{\alpha_{\pi \mathrm{M}}}\right)>0 .
$$

Note that both terms on the left hand side equal zero if $\alpha_{\pi \mathrm{M}}=\alpha_{\pi \mathrm{F}} /(\kappa+1)$ and are negative if $0<\alpha_{\pi \mathrm{M}}<\alpha_{\pi \mathrm{F}} /(\kappa+1)$.

F: Behavior of second-period inflation as function of $\alpha_{\pi M}$ for given $\alpha_{\pi F}$.

Second-period inflation can be written as, 


$$
\pi_{2}=\left(\frac{1 / \alpha_{\pi M}}{\beta_{S}^{*}(1+\rho) N_{D}^{*}+N_{D}}\right)\left((1+\rho)\left(\tilde{K}_{1}+(1+\rho) d_{0}\right)+\tilde{K}_{2}\right) .
$$

Differentiate the first factor between brackets with respect to $\alpha_{\pi \mathrm{M}}$, to yield,

$$
\frac{-\left(\frac{1}{\alpha_{\pi \mathrm{M}}^{2}}\right)\left(1+\beta_{\mathrm{S}}^{*}(1+\rho)\right)\left(\frac{1}{v^{2}}+\frac{1}{\alpha_{\mathrm{gS}}}\right)+\beta_{\mathrm{S}}^{*}(1+\rho)\left(\frac{\alpha_{\pi \mathrm{F}}}{\alpha_{\pi \mathrm{M}}^{4}}\right)}{\left(\beta_{\mathrm{S}}^{*}(1+\rho)\left(\frac{\alpha_{\pi \mathrm{F}}}{\alpha_{\pi \mathrm{M}}^{2}}+\frac{1}{v^{2}}+\frac{1}{\alpha_{\mathrm{gS}}}\right)+\left(\frac{\kappa}{\alpha_{\pi \mathrm{M}}}+\frac{1}{v^{2}}+\frac{1}{\alpha_{\mathrm{gS}}}\right)\right)^{2}} .
$$

Expression (F.1) is positive for $0 \leq \alpha_{\pi \mathrm{M}}<\left\{\left[\beta_{\mathrm{S}}{ }^{*}(1+\rho) \alpha_{\pi \mathrm{F}}\right] /\left[\left(1+\beta_{\mathrm{S}}{ }^{*}(1+\rho)\right)\left(1 / v^{2}+1 / \alpha_{\mathrm{gS}}\right)\right]\right\}^{1 / 2}$ and negative for $f_{\mathrm{M}}>$ $\left\{\left[\beta_{\mathrm{S}}{ }^{*}(1+\rho) \alpha_{\pi \mathrm{F}}\right] /\left[\left(1+\beta_{\mathrm{S}}{ }^{*}(1+\rho)\right)\left(1 / v^{2}+1 / \alpha_{\mathrm{gS}}\right)\right]\right\}^{1 / 2}$. Hence, ${ }_{2} \pi$ reaches a global maximum at ${ }_{\pi} \alpha^{*}=\alpha \equiv$ $\left\{\left[\beta_{S}{ }^{*}(1+\rho) \alpha_{\pi \mathrm{F}} \mathrm{I} /\left[\left(1+\beta_{\mathrm{S}}{ }^{*}(1+\rho)\right)\left(1 / v^{2}+1 / \alpha_{\mathrm{gS}}\right)\right]\right\}^{1 / /}\right.$.

G: Proof of (5.3), the condition under which (for $\kappa<1$ ) second period inflation is lower with decentralized discretion than with centralized commitment.

Assume that $k<1$. Using Table 1 and the assumption that the authorities' price stability weights coincide with society's, we find that second period inflation is lower with decentralized discretion than with centralized commitment if and only if,

$$
\begin{gathered}
\left(\frac{\kappa / \alpha_{\pi \mathrm{S}}}{\mathrm{P}}\right)\left(\frac{(1+\rho) \tilde{\mathrm{F}}}{\beta_{\mathrm{F}}^{*}(1+\rho)+1}\right)>\left(\frac{1 / \alpha_{\pi \mathrm{S}}}{\mathrm{N}_{\mathrm{D}}}\right)\left(\frac{(1+\rho) \tilde{\mathrm{F}}}{\beta_{\mathrm{F}}^{*}\left(\mathrm{~N}_{\mathrm{D}}^{*} / \mathrm{N}_{\mathrm{D}}\right)(1+\rho)+1}\right) \rightarrow \\
\beta_{\mathrm{F}}^{*}(1+\rho)\left(\mathrm{P}-\kappa \mathrm{N}_{\mathrm{D}}^{*}\right)+\left(\mathrm{P}-\kappa \mathrm{N}_{\mathrm{D}}\right)<0 \Leftrightarrow \\
\beta_{\mathrm{F}}^{*}(1+\rho)\left(\frac{\kappa(\kappa-1)}{\alpha_{\pi \mathrm{S}}}+(1-\kappa)\left(\frac{1}{v^{2}}+\frac{1}{\alpha_{\mathrm{gS}}}\right)\right)+(1-\kappa)\left(\frac{1}{v^{2}}+\frac{1}{\alpha_{\mathrm{gS}}}\right)<0 .
\end{gathered}
$$

Divide by $(\kappa-1)(<0)$ to give,

$$
\begin{gathered}
\beta_{\mathrm{F}}^{*}(1+\rho)\left(\frac{\kappa}{\alpha_{\pi \mathrm{S}}}-\left(\frac{1}{v^{2}}+\frac{1}{\alpha_{\mathrm{gS}}}\right)\right)-\left(\frac{1}{v^{2}}+\frac{1}{\alpha_{\mathrm{gS}}}\right)>0 \Leftrightarrow \\
\beta_{\mathrm{F}}^{*}(1+\rho)\left(\frac{\kappa}{\alpha_{\pi \mathrm{S}}}\right)>\left(\beta_{\mathrm{F}}^{*}(1+\rho)+1\right)\left(\frac{1}{v^{2}}+\frac{1}{\alpha_{\mathrm{gS}}}\right) .
\end{gathered}
$$

Divide both sides by the right hand side of (G.1) to yield (5.3).

H: Optimal central bank weight in the presence of political distortions. 
One can write society’s welfare loss as

$$
\mathrm{L}_{\mathrm{A}} \mathrm{L}_{\mathrm{B}} \mathrm{F}^{2}
$$

where

$$
\begin{gathered}
\mathrm{L}_{\mathrm{A}} \equiv\left(\frac{\frac{\alpha_{\pi \mathrm{S}}}{\alpha_{\pi \mathrm{M}}^{2}}+\frac{1}{v^{2}}+\frac{1}{\alpha_{\mathrm{gS}}}}{2 \mathrm{~N}_{\mathrm{D}}^{2}}\right)>0, \\
\mathrm{~L}_{\mathrm{E}} \equiv\left(\frac{(1+\rho)^{2}\left(\left(\beta_{\mathrm{ND}}^{*}\right)^{2}+\beta_{\mathrm{S}}\right)}{\left(\beta_{\mathrm{ND}}^{*}(1+\rho)+1\right)^{2}}\right)>0 .
\end{gathered}
$$

Let us first establish some properties of $\mathrm{L}_{\mathrm{A}}$, the intratemporal component of the welfare loss, and $\mathrm{I}_{\mathrm{B}}$, the intertemporal component of the welfare loss.

Differentiate $\mathrm{L}_{\mathrm{A}}$ with respect to $\alpha_{\pi \mathrm{M}}$, to yield,

$$
\frac{\partial \mathrm{L}_{\mathrm{A}}}{\partial \alpha_{\pi \mathrm{M}}}=\left(\frac{\frac{1}{\alpha_{\pi \mathrm{M}}^{2}}\left(\kappa-\frac{\alpha_{\pi \mathrm{S}}}{\alpha_{\pi \mathrm{M}}}\right)\left(\frac{1}{v^{2}}+\frac{1}{\alpha_{\mathrm{gS}}}\right)}{\mathrm{N}_{\mathrm{D}}^{3}}\right)
$$

Hence, $\mathrm{L}_{\mathrm{A}}$ is decreasing (increasing) for $\alpha_{\pi \mathrm{M}}<(>) \alpha_{\pi \mathrm{S}} / \mathrm{\kappa}$ so that it reaches its global minimum at $\alpha_{\pi \mathrm{M}}=\alpha_{\pi \mathrm{S}} / \mathrm{\kappa}$.

Differentiate $\mathrm{L}_{\mathrm{E}}$ with respect to $\alpha_{\pi \mathrm{M}}$, to yield,

$$
\frac{\partial L_{E}}{\partial \alpha_{\pi M}}=2(1+\rho)^{2}\left(\frac{\beta_{N D}^{*}-\beta_{S}^{*}}{\left(\beta_{N D}^{*}(1+\rho)+1\right)^{3}}\right)\left(\frac{\partial \beta_{N D}^{*}}{\partial \alpha_{\pi M}}\right) \text {. }
$$

The first factor between square brackets on the right hand side of (H.5) is negative (positive) if $\beta_{\mathrm{ND}}{ }^{*}<(>) \beta_{\mathrm{S}}{ }^{*}$. Furthermore,

$$
\frac{\partial \beta_{\mathrm{ND}}^{*}}{\partial \alpha_{\pi \mathrm{M}}}=\left(\frac{-\frac{\kappa \alpha_{\pi \mathrm{F}}}{\alpha_{\pi \mathrm{M}}^{4}}+\frac{1}{\alpha_{\pi \mathrm{M}}^{2}}\left(\kappa-2\left(\frac{\alpha_{\pi \mathrm{F}}}{\alpha_{\pi \mathrm{M}}}\right)\right)\left(\frac{1}{v^{2}}+\frac{1}{\alpha_{\mathrm{gS}}}\right)}{\mathrm{N}_{\mathrm{D}}^{2}}\right) \beta_{\mathrm{F}}^{*}
$$

which is negative for values of $\alpha_{\pi \mathrm{M}} \leq 2 \alpha_{\pi \mathrm{F}} / \mathrm{k}$.

$$
\text { H1: Proof that } \alpha_{\pi M}{ }^{E}<\alpha_{\pi M}{ }^{o p t}<\alpha_{\pi d} \text { / } \kappa \text { if } \beta_{F}<\beta_{S} \text { and } \alpha_{\pi F}=\alpha_{\pi S}
$$

(where $\alpha_{\pi M}{ }^{E}>0$ is defined as the value of $\alpha_{\pi M}$ which minimizes the intratemporal loss factor).

The proof consists of the following steps, in which we show that: (i) $\mathrm{L}_{\mathrm{E}}$ reaches its global minimum 
at $\alpha_{\pi M}=\alpha_{\pi M}{ }^{\mathrm{E}}$, where $0<\alpha_{\pi \mathrm{M}}{ }^{\mathrm{E}}<\alpha_{\pi \mathrm{S}} / \mathrm{K}$; (ii) $\mathrm{L}_{\mathrm{A}}$ is decreasing for $\alpha_{\pi \mathrm{M}} \leq \alpha_{\pi \mathrm{M}}{ }^{\mathrm{E}}$ and $\mathrm{L}_{\mathrm{B}}$ is decreasing for $\alpha_{\pi \mathrm{M}}<\alpha_{\pi \mathrm{M}}{ }^{\mathrm{E}}$, hence there exists a value of $\alpha_{\pi M}>\alpha_{\pi M}{ }^{\mathrm{E}}$, such that society's welfare loss is lower than for any $0<\alpha_{M M} \leq \alpha_{M M}{ }^{\mathrm{E}}$; (iii) $\mathrm{I}_{\mathrm{L}}$, when evaluated at $\alpha_{\pi \mathrm{M}}=\alpha_{\pi \mathrm{s}} / \kappa$, is increasing and is lower than when evaluated at any other $\sigma_{\pi}>Q \varepsilon / \kappa$. Given that $L_{A}$ reaches a global minimum for $f_{M}=\alpha_{S} / K$ (the minimum is interior, hence the slope of ${ }_{A} L$ is flat at $\alpha_{\pi \mathrm{M}}=\alpha_{\pi \mathrm{S}} \mathrm{s} / \mathrm{K}$ and, hence, there are no first-order effects on $\mathrm{I}_{\mathrm{A}}$ of a change in $\alpha_{\mathrm{M}}$ when evaluated at $\alpha_{\mathrm{M}}=\alpha_{\mathrm{S}} / \mathrm{K}$ ), it then follows that $\alpha_{\pi M}{ }^{\mathrm{E}}<\alpha_{\pi \mathrm{M}}{ }^{\mathrm{opt}}<\alpha_{\pi \mathrm{S}} / \mathrm{K}$.

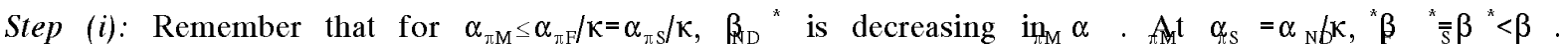
Moreover, $\beta_{\mathrm{ND}}{ }^{*}$ goes to infinity as $\alpha_{\pi \mathrm{M}}$ approaches zero from above. Hence, by continuity, there is a (unique) value of $\alpha_{\pi \mathrm{M}}$, denoted by $\alpha_{\mathrm{M}}{ }^{\mathrm{E}}$, between 0 and ${ }_{\pi} \mathrm{g}^{\alpha} / \mathrm{K}$ at which $_{\mathrm{NI}} \beta^{*}=\beta_{\mathrm{B}} \mathrm{L}$ reaches its global minimum at $\beta_{\mathrm{ND}}{ }^{*}=\beta_{\mathrm{S}}{ }^{*}$, hence at $\alpha_{\pi \mathrm{M}}=\alpha_{\pi \mathrm{M}}{ }^{\mathrm{E}}$.

Step (ii): Because $\alpha_{\pi \mathrm{M}}{ }^{\mathrm{E}}<\alpha_{\pi \mathrm{S}} / \mathrm{\kappa}$, it follows immediately that $\mathrm{I}_{\mathrm{A}}$ is decreasing for $q_{\mathrm{M}} \leq \boldsymbol{q}_{\mathrm{M}}{ }^{\mathrm{E}}$. Moreover, we have

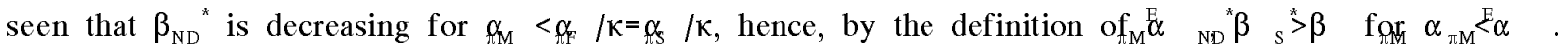
Hence, for $\alpha_{\pi \mathrm{M}}<\alpha_{\pi \mathrm{M}}{ }^{\mathrm{E}}, \partial \mathrm{L}_{\mathrm{F}} / \partial \beta_{\mathrm{ND}}{ }^{*}>0$ and $\partial \beta_{\mathrm{ND}}{ }^{*} / \partial \alpha_{\pi \mathrm{M}}<0$, and, hence, $\partial \mathrm{L}_{\mathrm{F}} / \partial \alpha_{\pi \mathrm{M}}<0$.

Step (iii): Remember that at $\alpha_{\pi \mathrm{M}}=\alpha_{\pi \mathrm{S}} / \mathrm{\kappa}, \beta_{\mathrm{ND}}{ }^{*}=\beta_{\mathrm{F}}{ }^{*}<\beta_{\mathrm{S}}{ }^{*}$, and, hence, $\partial \mathrm{I}_{\mathrm{R}} / \partial \beta_{\mathrm{ND}}{ }^{*}<0$ at $\alpha_{\mathrm{TM}}=\alpha_{\mathrm{tS}} / \mathrm{K}$. Remember also that $\beta_{\mathrm{ND}}{ }^{*}$ is decreasing $\mathrm{at}_{\mathrm{M}} \alpha_{\pi} \overline{\overline{\mathrm{S}}} \alpha / \mathrm{\kappa}$. Therefore $\partial_{\mathrm{MM}} / \partial \alpha>0_{\mathrm{M}}$ at ${ }_{\pi} \alpha^{\alpha}=\alpha / \kappa$. Furthermore $\mathrm{N} / \mathrm{N}=1$ at $\alpha_{\pi \mathrm{M}}=\alpha_{\pi \mathrm{S}} / \kappa$, while $\mathrm{N}_{\mathrm{D}}{ }^{*} / \mathrm{N}_{\mathrm{D}}<1$ for $\alpha_{\pi \mathrm{M}}>\alpha_{\pi \mathrm{S}} / \kappa$, as is easy to check. Hence, for $\alpha_{\pi \mathrm{M}}>\alpha_{\pi \mathrm{S}} / \kappa, \beta_{\mathrm{ND}}{ }^{*}<\beta_{\mathrm{F}}{ }^{*}<\beta_{\mathrm{S}}{ }^{*}$. Because $\mathrm{L}_{\mathrm{E}}$ is monotonically decreasing in $\beta_{\mathrm{ND}}{ }^{*}$ for $\beta_{\mathrm{ND}}{ }^{*}<\beta_{\mathrm{S}}{ }^{*}, \mathrm{I}_{\mathrm{B}}$ when evaluated at $\alpha_{\mathrm{H}}=\alpha_{\mathrm{f}} / \mathrm{\kappa}$ (hence $\boldsymbol{N}^{*} \quad \overline{\overline{\mathrm{F}}} \boldsymbol{\beta}$ ) must be lower than $L_{E}$, when evaluated at some $\alpha_{\pi M}>\alpha_{\pi S} / \kappa$.

$$
\text { H2: Proof that } \alpha_{\pi M}^{o p t}>\alpha_{\pi H} / \kappa \text { if } \alpha_{\pi F}<\alpha_{\pi S} \text { and } \beta_{F}=\beta_{S}
$$

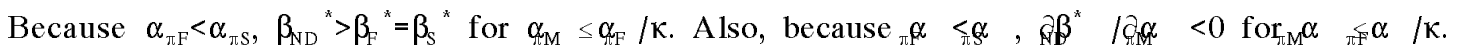
Hence, $L_{\mathrm{B}}$ is decreasing for $\alpha_{\pi \mathrm{M}} \leq \alpha_{\pi \mathrm{F}} / \kappa$. Finally, because $\alpha_{\pi \mathrm{F}}<\alpha_{\pi \mathrm{S}}, \mathrm{I}_{\mathrm{A}}$ is decreasing for $\alpha_{\pi \mathrm{M}} \leq \alpha_{\pi \mathrm{F}} / \kappa$. Hence, $\mathrm{I}_{\mathrm{A}} \mathrm{I}_{\mathrm{B}}$ is decreasing for $\alpha_{\pi \mathrm{M}} \leq \alpha_{\pi \mathrm{F}} / \kappa$ and, hence, the optimal inflation weight of the central bank is greater than $\pi_{f} / \kappa$ (and potentially infinitely large). 